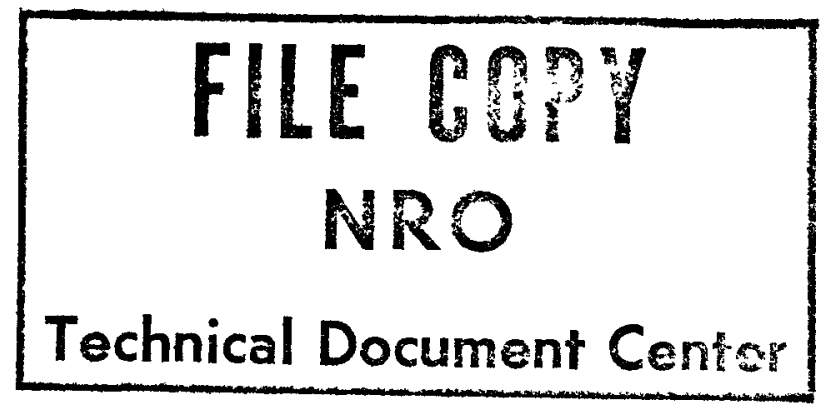

S056-CP090205-FI

TIME LINE SHEETS

NERVA Program, Contract SNP-1

September 1970

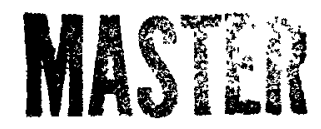

DISTRIBUTION OF THIS DOCUMENT UNLIMITED

(1)

AEROJET NUCLEAR SYSTEMS COMPANY

A DIVISION OF AEROJET-GENERAL $\Theta$

TECHNICAL DOCUMENT CENTER

Nuclear Rocket Operations

DOC. N0. $21-2263$

AGCS $0120-48$

20982 


\section{DISCLAIMER}

This report was prepared as an account of work sponsored by an agency of the United States Government. Neither the United States Government nor any agency Thereof, nor any of their employees, makes any warranty, express or implied, or assumes any legal liability or responsibility for the accuracy, completeness, or usefulness of any information, apparatus, product, or process disclosed, or represents that its use would not infringe privately owned rights. Reference herein to any specific commercial product, process, or service by trade name, trademark, manufacturer, or otherwise does not necessarily constitute or imply its endorsement, recommendation, or favoring by the United States Government or any agency thereof. The views and opinions of authors expressed herein do not necessarily state or reflect those of the United States Government or any agency thereof. 


\section{DISCLAIMER}

Portions of this document may be illegible in electronic image products. Images are produced from the best available original document. 


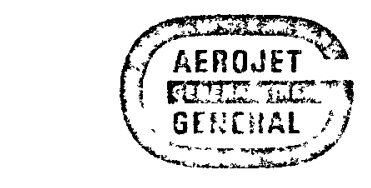

S056-CP090205-FI

\title{
TIME LINE SHEETS
}

\section{NERVA Program

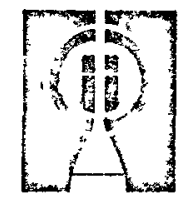 \\ Contract SNP-1}

September 1970

\begin{abstract}
This report was prepared as an account of work sponsored by the United States Government. Neither the United States nor the United States Energy Research and Development Administration, nor any of their employees, nor any of their contractors, subcontractors, or their employees, makes any warranty, express or implied, or assumes any legal liability or responsibility for the accuracy, completeness or usefulness of any information, apparatus, product or process disclosed, or represents that its use would not infringe privately owned rights.
\end{abstract}

NOTICE

\begin{tabular}{|c|c|}
\hline $\begin{array}{c}\text { Classification } \\
\text { UNCLASSIF }\end{array}$ & $\begin{array}{l}\text { egory } \\
\text { D }\end{array}$ \\
\hline$\frac{y^{\prime} \text { (andiand }}{\text { Classifying Officer }}$ & $\frac{q / 172}{\text { Date }}$ \\
\hline
\end{tabular}




\section{NERVA TIME LINE SHEETS \\ 8 BURN MISSION A - LUINAR - MANNED \\ BLOCK 2 LEVELS 1 AND 2 \\ BLOCK 1 LEVELS 1,2 AND 3}

A. These Time Line Sheets (TLS) display, by means of time based bar charts and pertinent commentary, nominal time data for 1 st and 2nd level functions of Block 2, Perform Launch and Boost Operations as well as nominal time data for 1st, 2nd and certain $3 \mathrm{rd}$ level functions of Block 1, Perform Missions (Nuclear Stage Operational Phase). These TLS were developed in conjunction with Functional Flow Diagrams (FFD) 1137311 released 2 September 1970 and related Requirement $\mathrm{s}$ Allocation Sheets (RAS) for 8 Burn Mission A - Lunar - Manned (A-L-M).

B. In addition to the data provided by the FFD/RAS, the following reference data sources were used in developing these TLS:

1. D. P. Book September 1970 memorandum 7410:0209 to J. J. Stewart subject: Launch Trajectory for INT-21/RNV.

2. Flight Engine Profile (FEP) 312058 Burn Mission printout dated 9 July 1970 has been used, per TLS General Note 14, in lieu of 8 Burn Mission A-L-M time data forthcoming in Data Item S-114, Reference Mission Data Book for NERVA Design.

3. T. E. Lavenda 19 January 1970 Memorandum 7410:0046M to L. E. Little, Subject: Mission Analysis Inputs for Requirements Allocation Sheets, A-L-M Block 1 and Block 2 Functions.

4. Scientific and Technical Aerospace Reports (STAR) \#N69-24692, Saturn V Launch Vehicle Flight Evaluation Report AS-503 Apollo 8 Mission.

5. It should be noted that due to the early submittal of this data item the NERVA Engine Operational Phases (Figure 2a through $2 \mathrm{~h}$ ) does not reflect the figure identified in current NERVA Engine Spe cification. 
C. The detailed display uses vertically striped bars for reference functions; black or black bordered bars for subsequent active functions subordinate to reference functions; dotted bars indicate functions involving intermittent/undefined or variable limits. General notes identified with some functions are us ed to supply additional pertinent information.

D. These TLS begin with the completion of FFD Block 3.2, Conduct Space Vehicle Countdown, 9 seconds before liftoff and continue progressively through Block 2 and Block 1 functions. Because of variable duration stays at an earth orbiting Propellant Depot Space Station (PDSS) and at a Lunar Space Station (LSS), six time bases have been used to display the mission progression through Block 2 and Block 1 functions on an interrupted basis. The six time bases are described in General Notes 1 through 6 on the first page of the TLS. Time bases are identified in the TLS where pertinent by the applicable General Note numbers.

E. This Mission A-L-M is based on an Earth to Moon round-trip shuttle at a non-optimum time which requires 8 burns of the NERVA Engine. The first four of these burns propel the Nuclear Vehicle from the vicinity of the PDSS located in a near-circular Earth orbit to the vicinity of the LSS located in a near-circular Lunar Polar orbit. The last four burns return the Nuclear Vehicle from the vicinity of the LSS to the vicinity of the PDSS.

On completion of a round trip shuttle mission between the Earth orbit and the Lunar orbit, the nuclear vehicle may be placed in Space Storage or more probably will be redocked to the PDSS and prepared for a subsequent mission. On completion of the normal useful life span of the NERVA engine, disposition will be made in conformity with space program requirements/directions. A gross schematic display of the sequence of events is shown in Figure 1 to facilitate quick correlation of mission events/functions/time bases. 
Mission A -L-M NERVA Full Flow Engine (FFE) Operational Phase Profiles are provided in Figu es 2 a through $2 \mathrm{~h}$ to display gross time values of the operations for each of the 8 burns of the NERVA Engine during this initial mission.

F. The following assumptions are included in the data displayed by these TLS.

1. Data not currently available from NERVA Program development has been taken from reference sources in certain instances on the basis of reasonable assumption: e.g., ignition time/launch time data. Liftoff is assumed to be range time 0.0 and the beginning of $T_{L B 1}$, the first time base per General Note 1 . Ignition for launch is assumed to be at minus 9 seconds on this time base in keeping with the approximately -9 seconds ignition time recorded for some S-1C stages on the Apollo Program . See General Note 13 .

2. The mission displayed is typical of an 8 Burn Mission A-L-M which makes no allowance for engine degradation due to use/age.

3. The round trip orbit to orbit circuit could be achieved with 4 Burns under optimum timing/circumstances. The additional burns used to achieve lunar polar orbit represent a potential safety requirement to ensure that a failure to obtain thrust on arrival at the lunar environs does not result in an orbit from which rescue would be very difficult if not impossible. The additional burns used to achieve transearth trajectory from the lunar polar orbit reflects a profile associated with the plausible assumption that a non-optimum ephemeris may exist for initiation of the transearth operations. 
4. The Abort Mission function 1.2.35 provides for malfunction/ contingency operations during the initial Impulse period of the NERVA engine for each mission. For a normal course of events, a complete success path is assumed otherwise; i. e., no other allowance has been made for failure, contingency operations or scheduled maintenance. 
NERVA 8 BURN MISSION A-L-M GROSS OVERALL FLIGHT OPERATIONAL SCHEMATIC SKETCH REF: 1137400 FULL FLOW ENGINE/7-9-70 FLIGHT ENGINE PROFILE (FEP) 31205 PRINTOUT D.P. BOOK SEPTEMBER 1970 MEMORANDUM 7410:0209 TO J.J. STEWART SUBJECT LAUNCH TRAJECTORY FOR INT-21/RNV

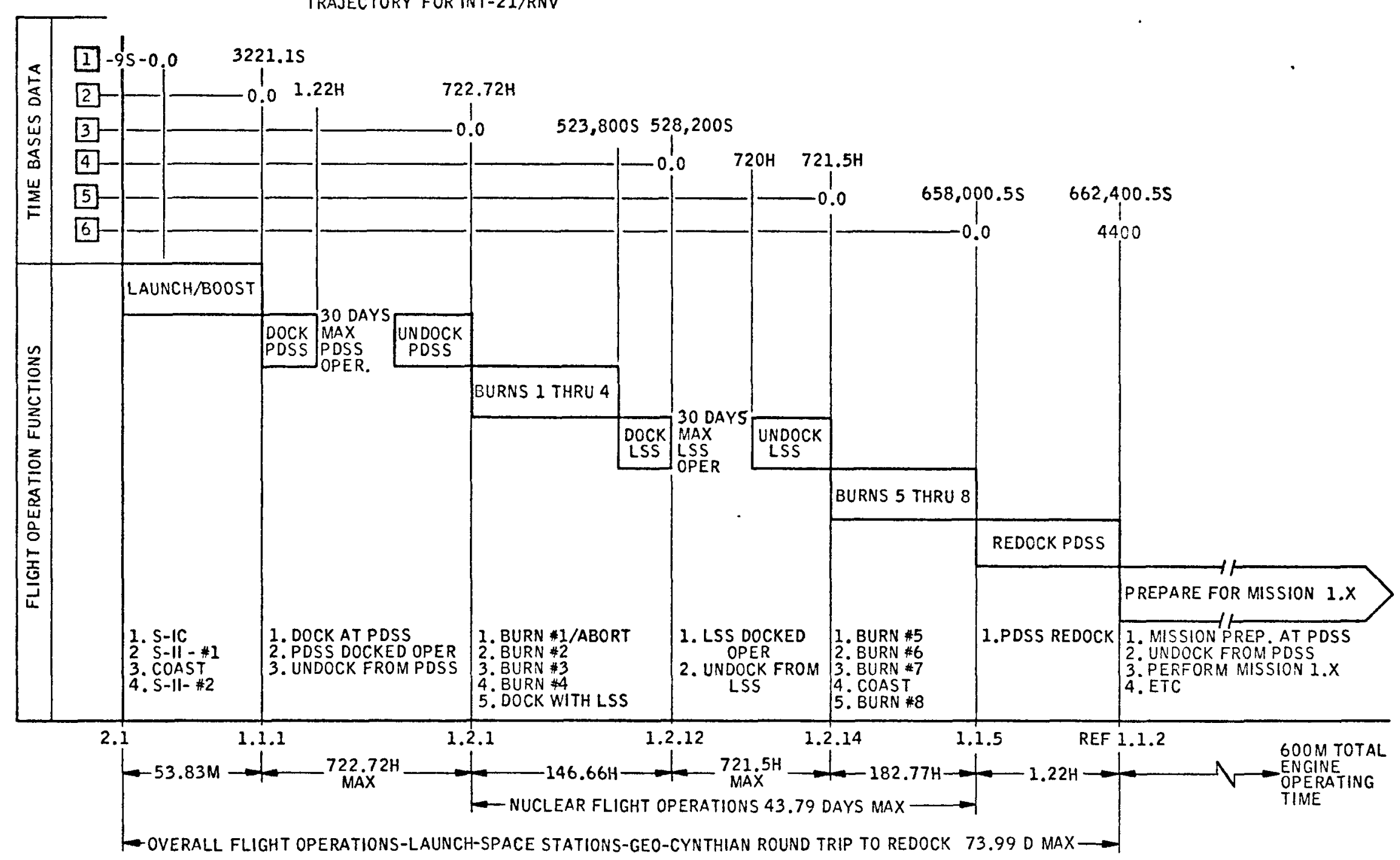

FIGURE 1 
IST BURN - 8 BURN MISSION A-L-M, 1137400 NERVA FULL FLOW ENGINE OPERATIONAL PHASE GROSS PROFILE DATA SOURCE: $1137400 / 2137250$ - 3 BURN A-L-M FEP 31205 PRINTOUT DATED 7-9-70

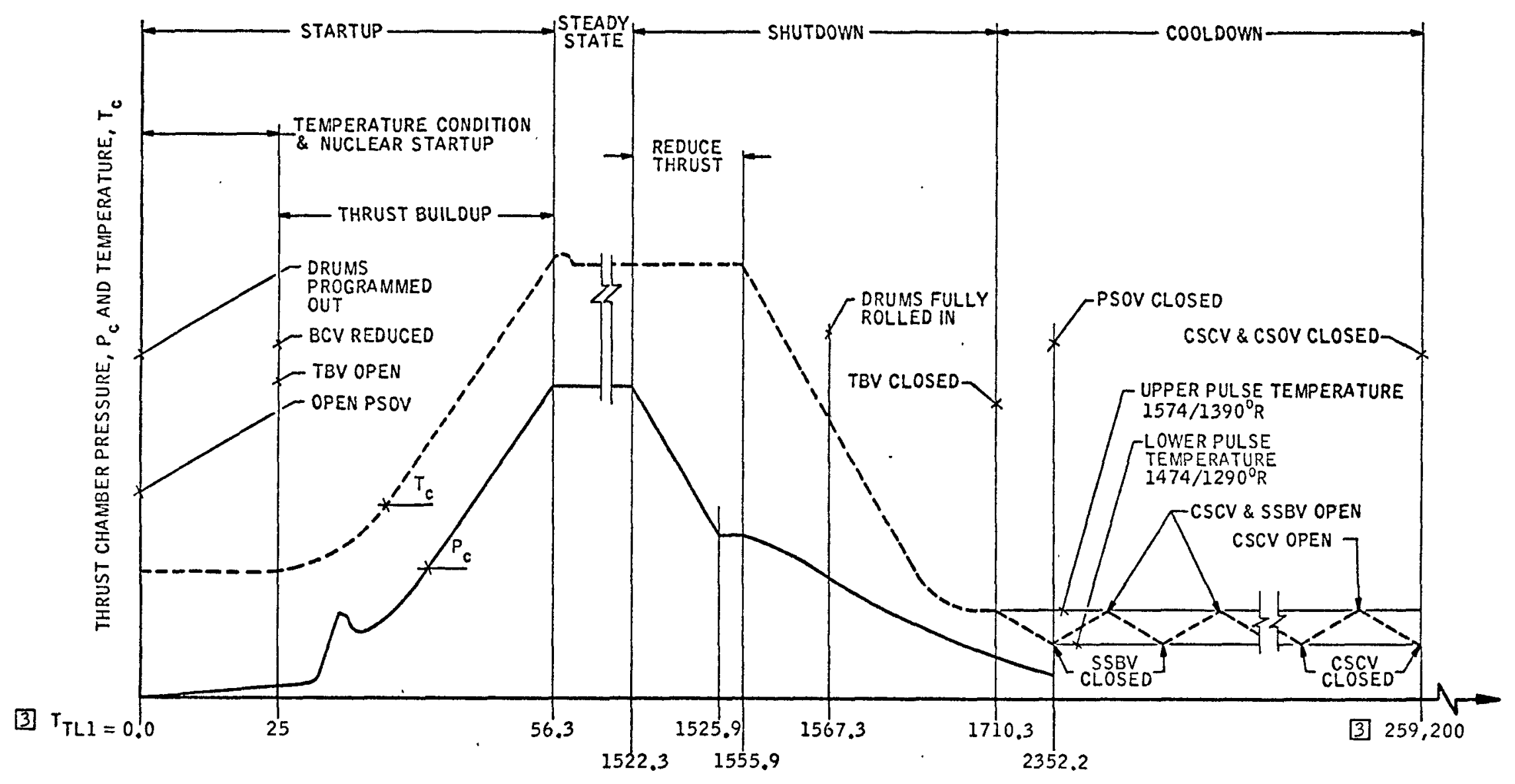

TIME (SECONDS UNLESS OTHERWISE INDICATED) 
2ND BURN - 8 BURN MISSION A-L-M, 1137400 NERVA FULL FLOW ENGINE OPERATIONAL PHASE GROSS PROFILE DATA SOURCE: $2137400 / 1137250$ - 8 BURN A-L-M FEP 31205 PRINTOUT DATED 7-9-70

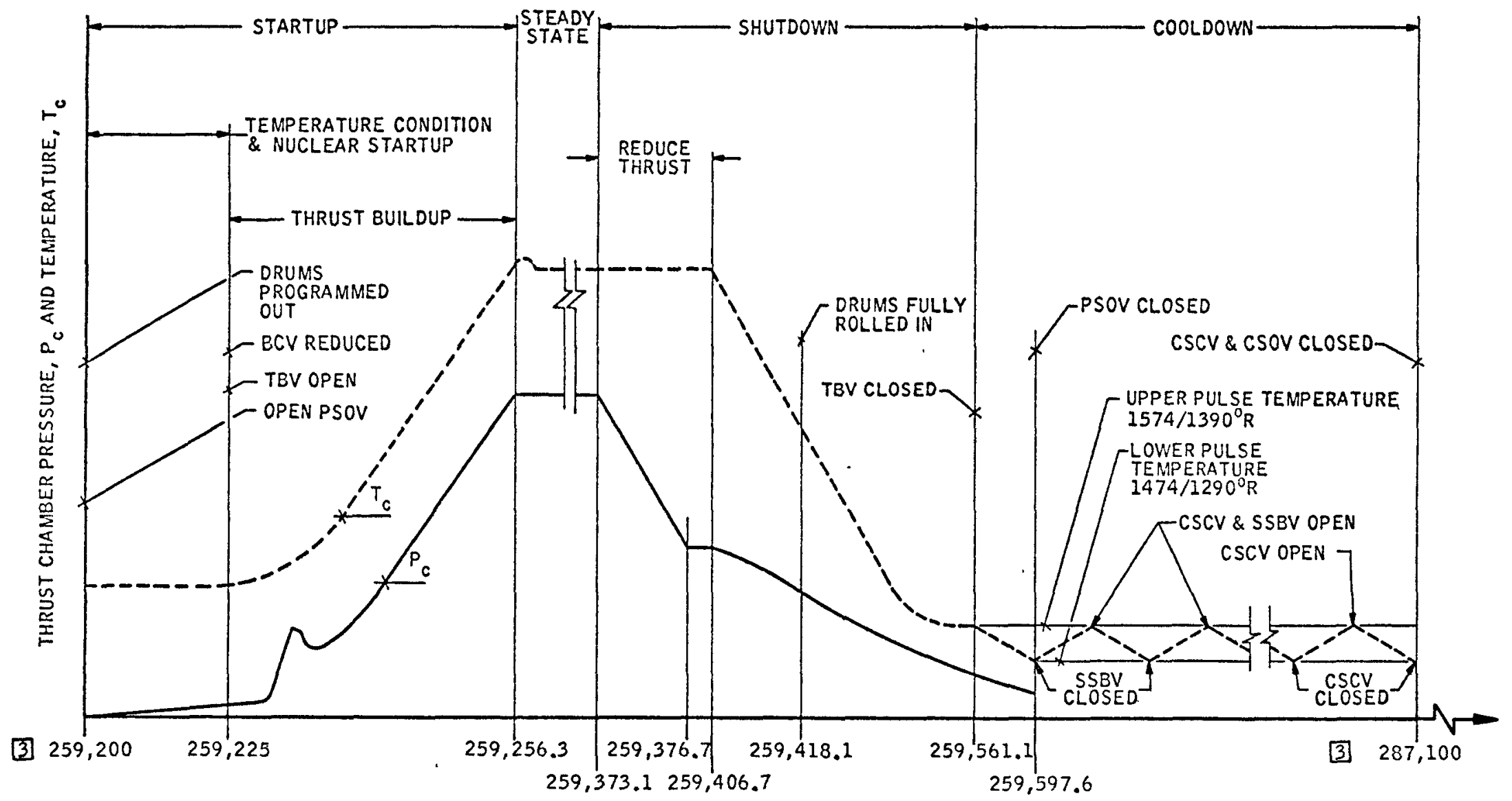

TIME (SECONDS UNLESS OTHERWISE INDICATED) 
3RD BURN - 8 BURN MISSION A-L-M, 1137400 NERVA FULL FLOW ENGINE OPERATIONAL PHASE GROSS PRDFILE DATA SOURCE: $1137400 / 1137250$ - 8 BURN A-L-M FEP 31205 PRINTOUT DATED 7-9-70

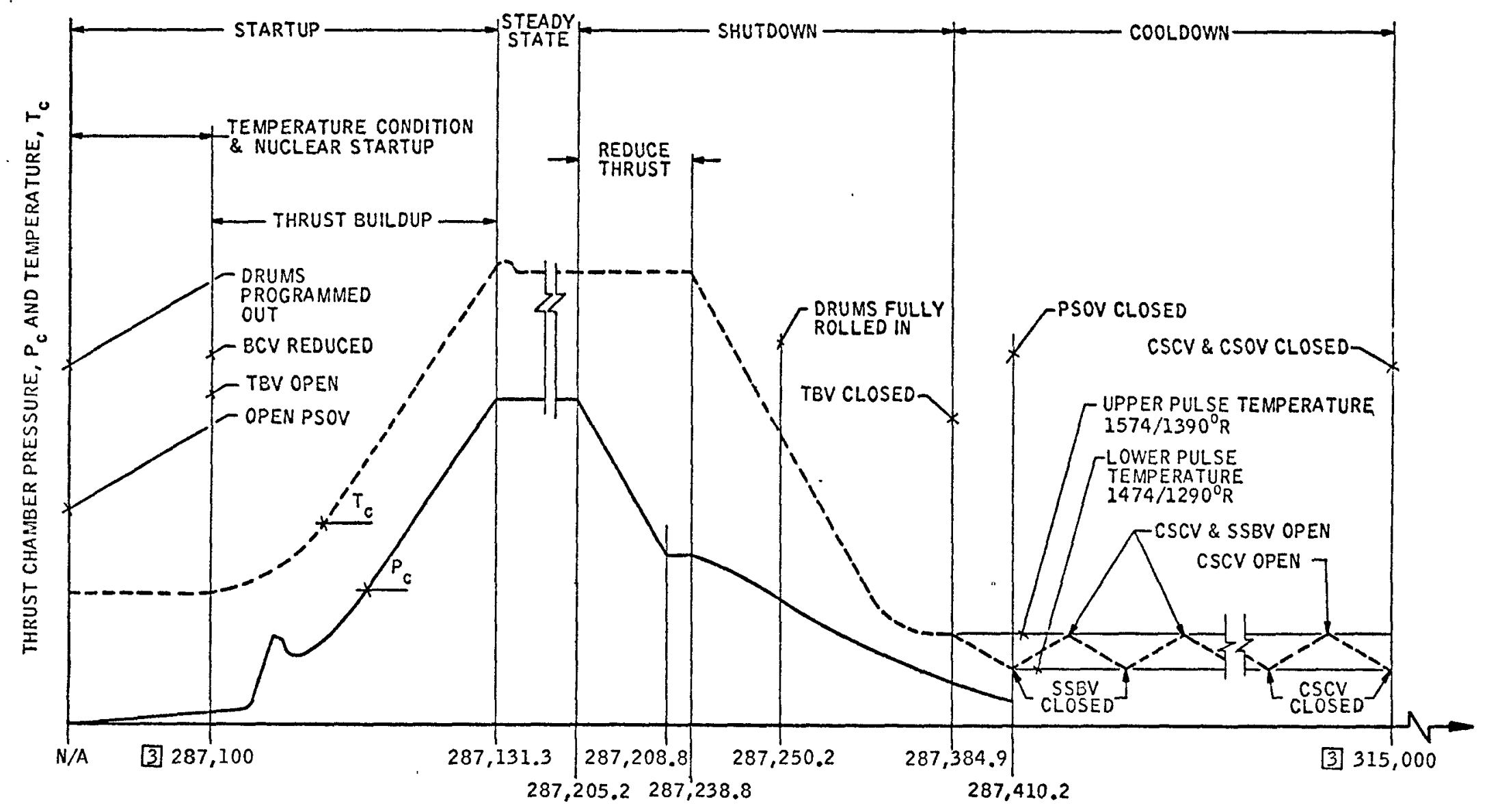

TIME (SECONDS UNLESS OTHERWISE INDICATED) 
4TH BURN AND LSS OPERATIONS - 8 BURN MIISSION A-L-M, 1137400 NERVA FULL FLOW ENGINE OPERATIONAL PHASE GROSS PROFILE

DATA SOURCE: $1137400 / 1137250$ - 8 EURN A-L-M FEP 31205 PRINTOUT DATED 7-9-70

*T.E. LAVENDA 19 JAN 1970 MEMO 7410:0046 TO L.E. LITTLE, SUBJECT: MISSION ANALYSIS INPUT FOR RAS A-L-M 1 \& 2

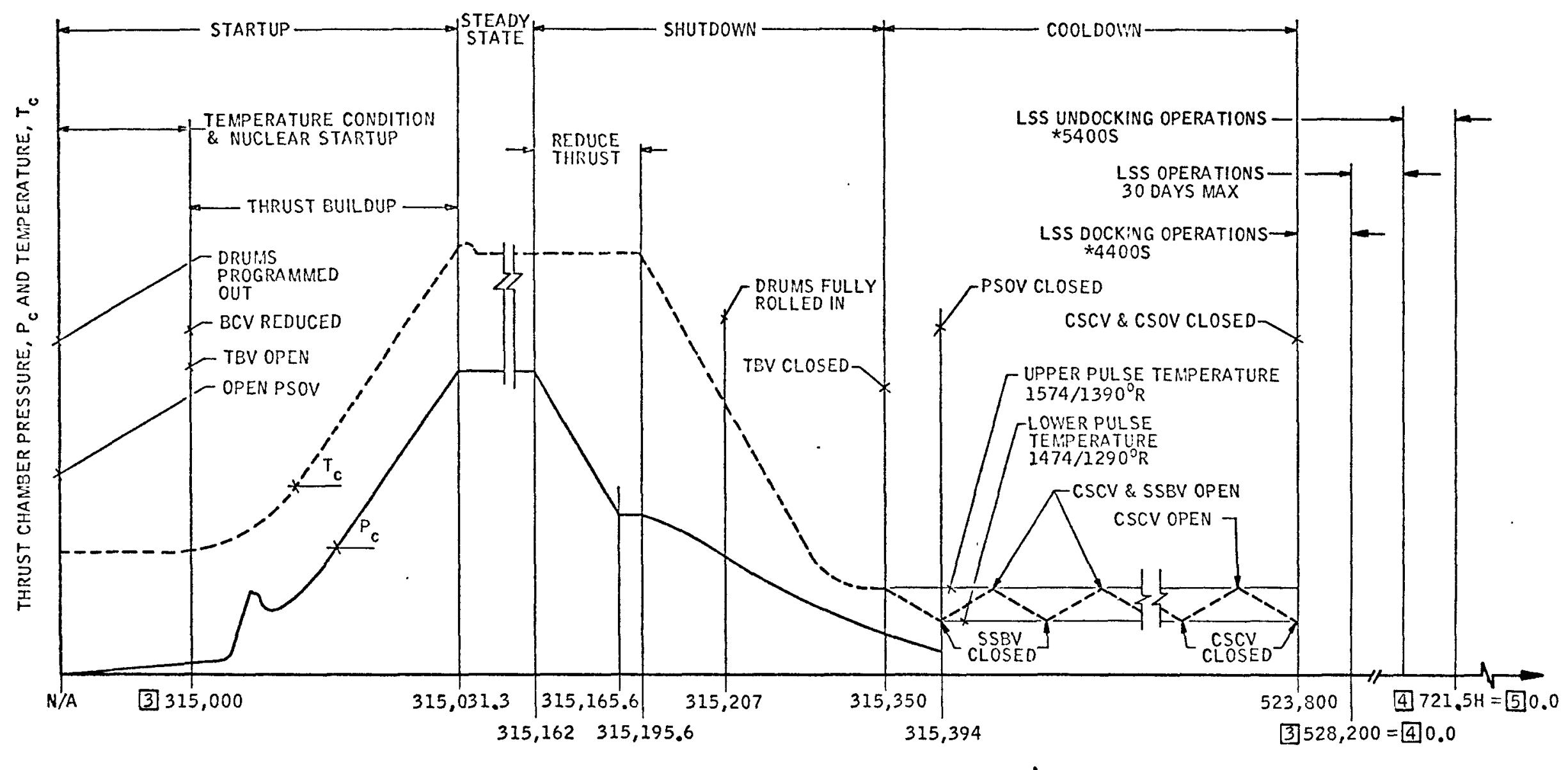

TIME (SECONDS UNLESS OTHERWISE INDICATED) 
5TH BURN - 8 BURN MISSION A-L-M, 1137400 NERVA FULL FLOW ENGINE OPERATIONAL PHASE GROSS PROFILE DATA SOURCE: $1137400 / 1137250$ - 8 BURN A-L-M FEP 31205 PRINTOUT DATED 7-9-70

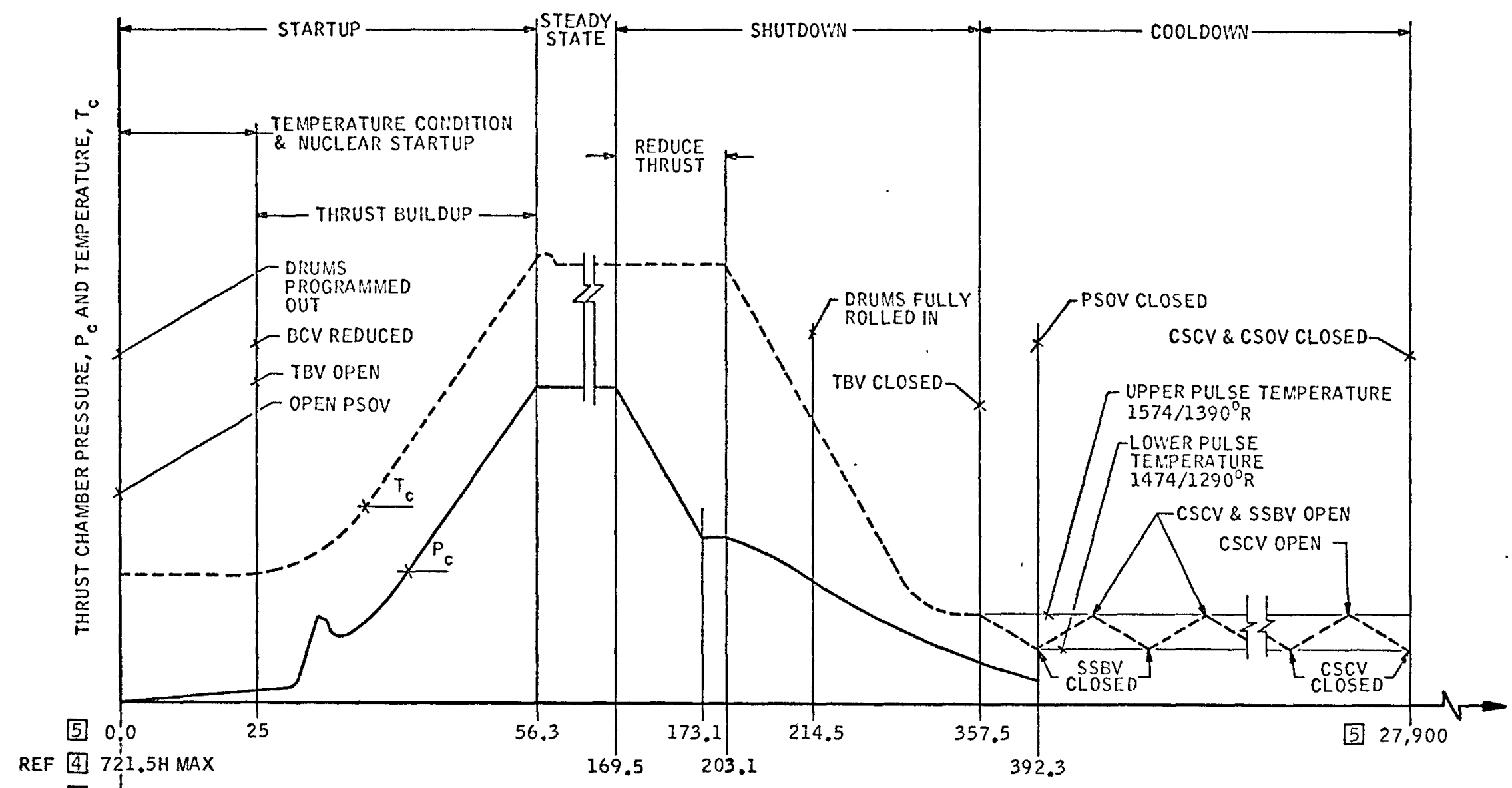

REF [3] 36.1759D MAX 
6TH BURN - 8 BURN MISSION A-L-M, 1137400 NERVA FULL FLOIV ENGINE OPERATIONAL PIIASE GROSS PRDFILE DATA SOURCE: $1137400 / 1137250$ - 8 BURN A-L-M FEP 31205 PRINTOUT DATED 7-9-70

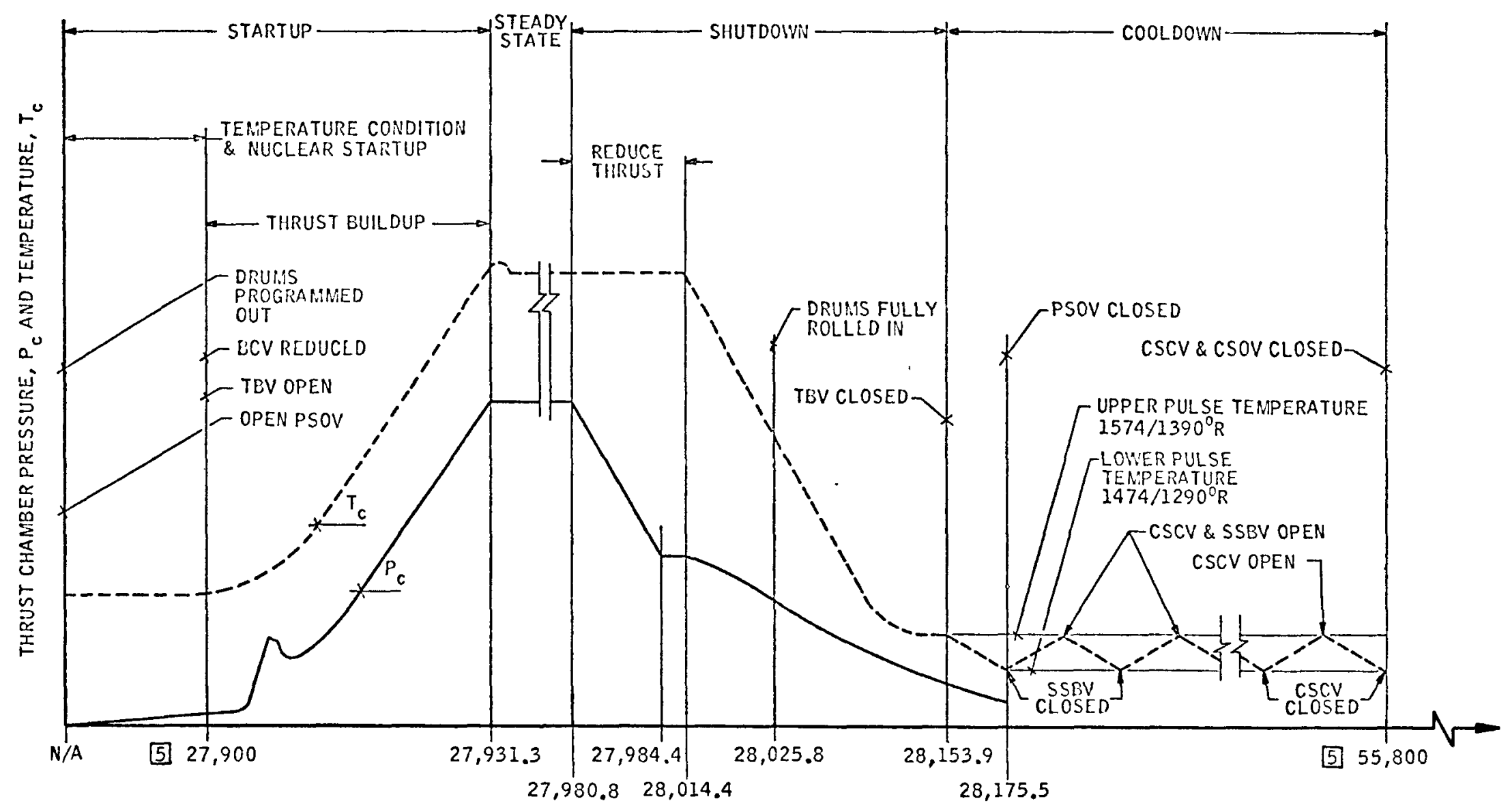

TIME (SECONDS U:LLESS OTHERWISE INDICATED) 
7TH BURN - 8 BURN MISSION A-L-M, 1137400 NERVA FULL FLOW ENGINE OPERATIONAL PHASE GROSS PRDFILE DATA SOURCE: $1137400 / 2137250$ - 8 BURN A-L-M FEP 31205 PRINTOUT DATED 7-9-70

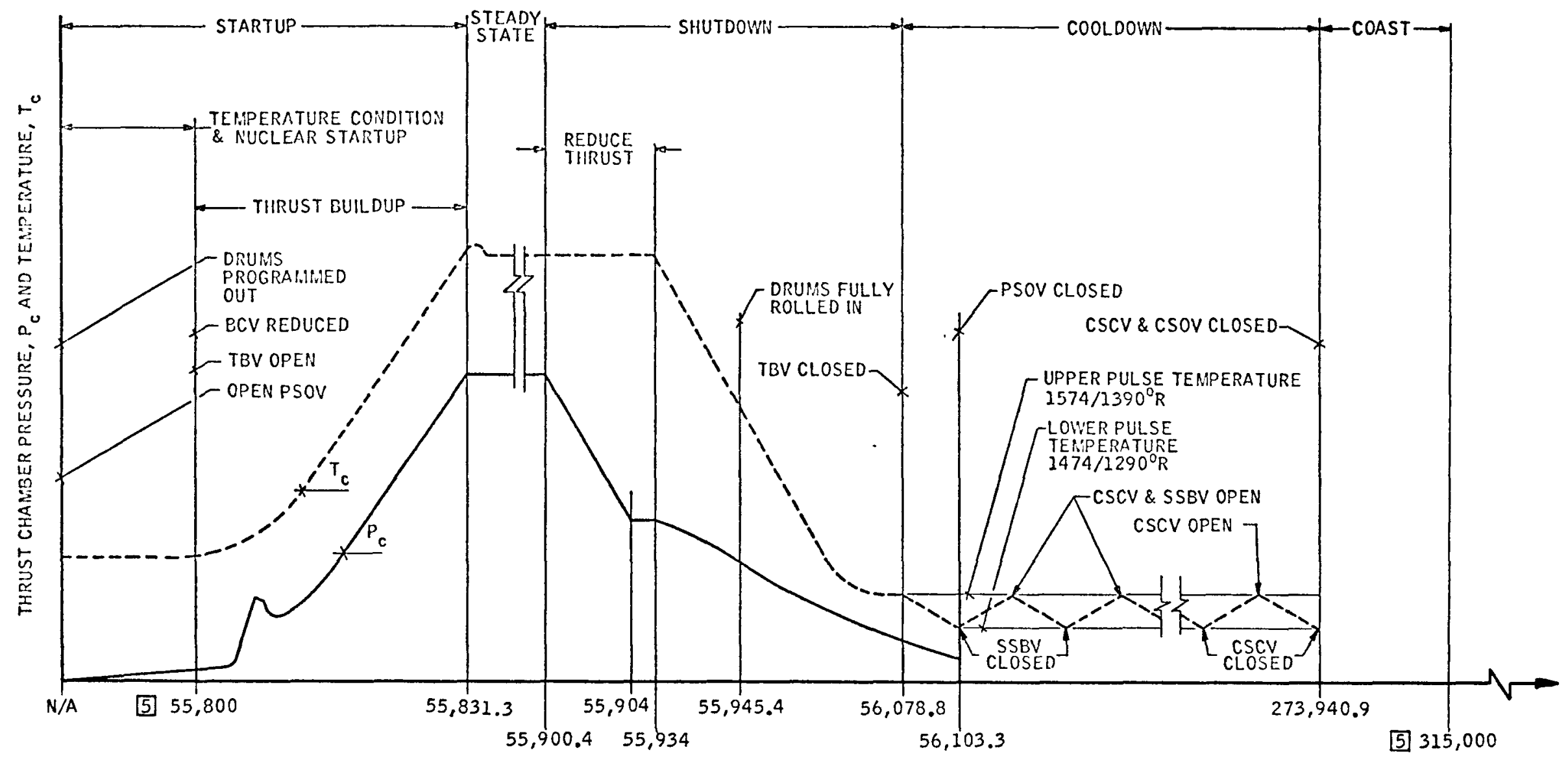

TIME (SECONDS UNLESS OTHERWISE INDICATED) 
8TH BURN AND REDOCK TO PDSS - 8 BUR: GISSION A-L-M, 1137400 NERVA FULL FLOW ENGINE OPERATIONAL PHASE GROSS PROFILE DATA SOURCE: $1137400 / 1137250$ - 8 BURN A-L-M FEP 31205 PRINTOUT DATED 7-9-70

*T.E. LAVENDA 19 JAN 1970 MEMO 7410:0046 TO L.E. LITTLE, SUBJECT: MISSION ANALYSIS INPUT FOR RAS A-L-M 1 \& 2

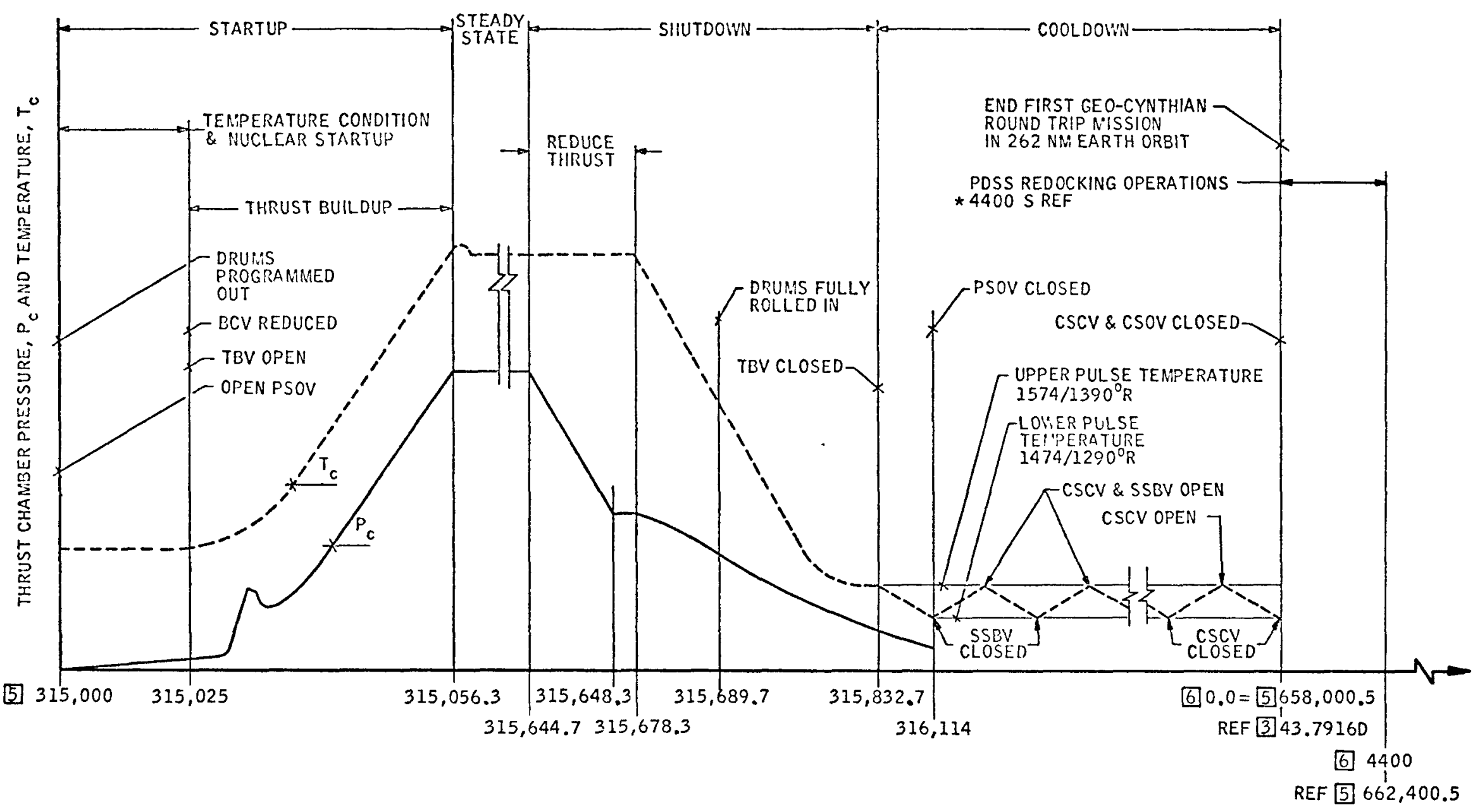

TIME (SECONDS UNLESS OTHERWISE INDICATED) 


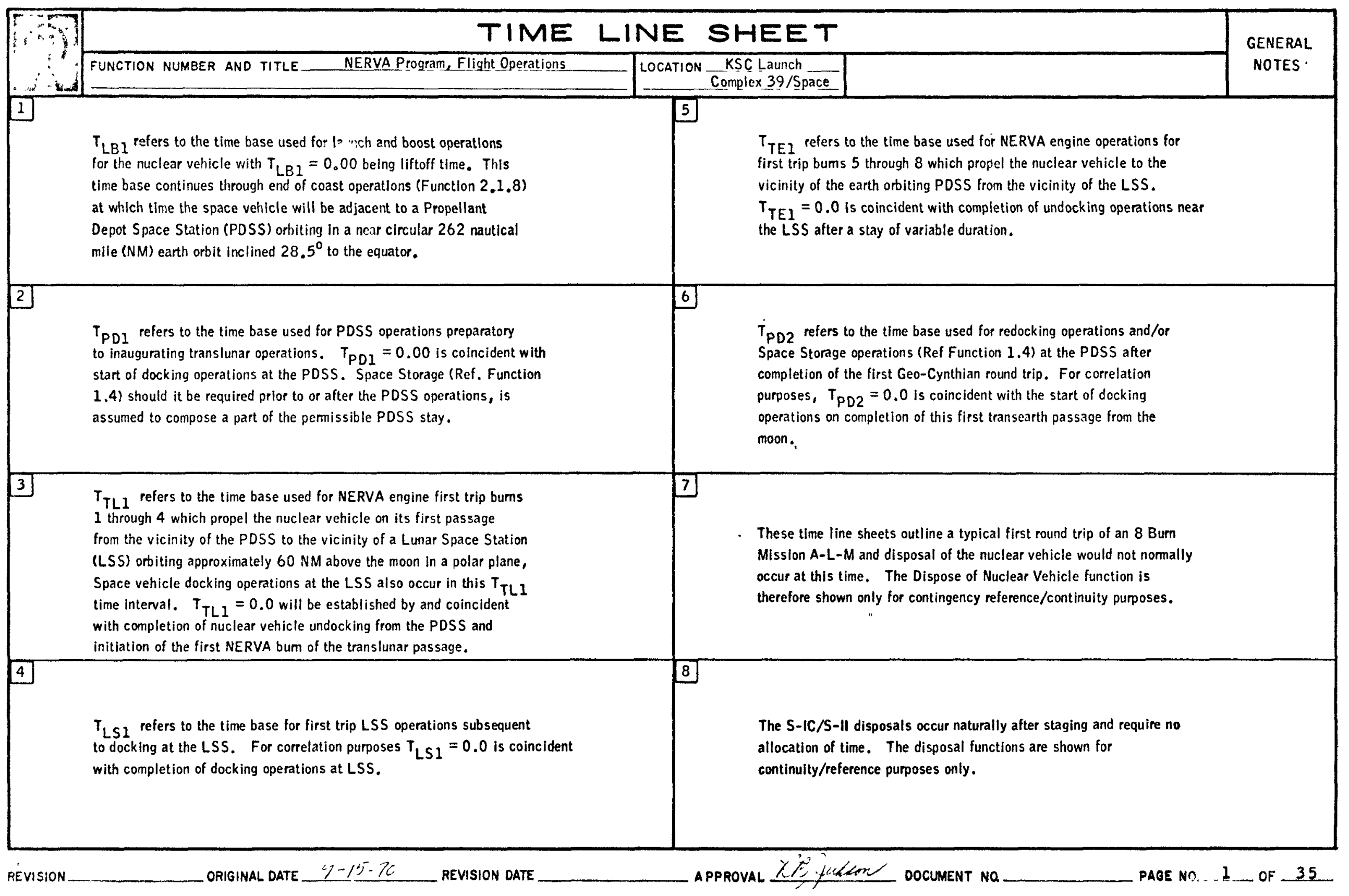




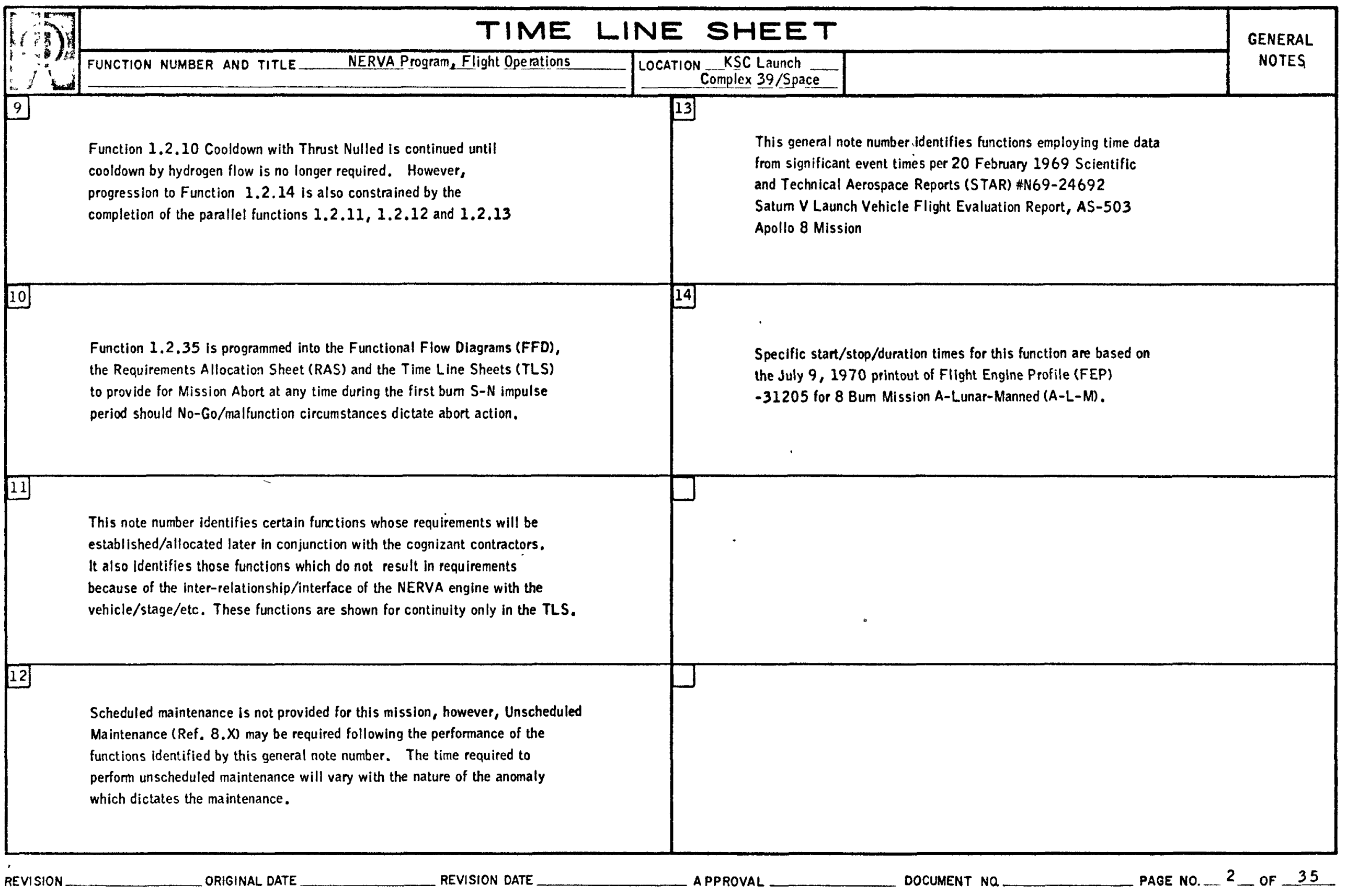




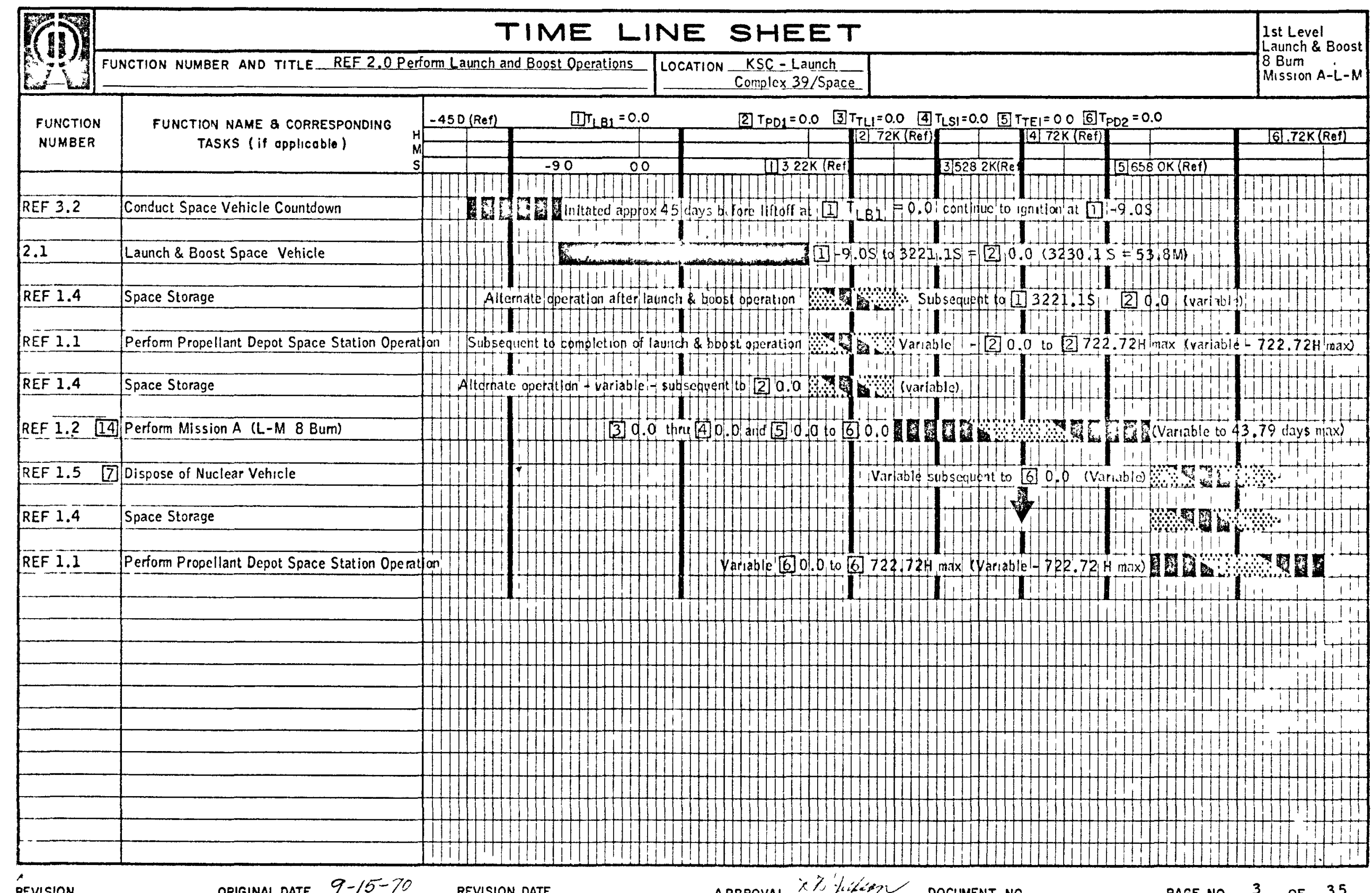




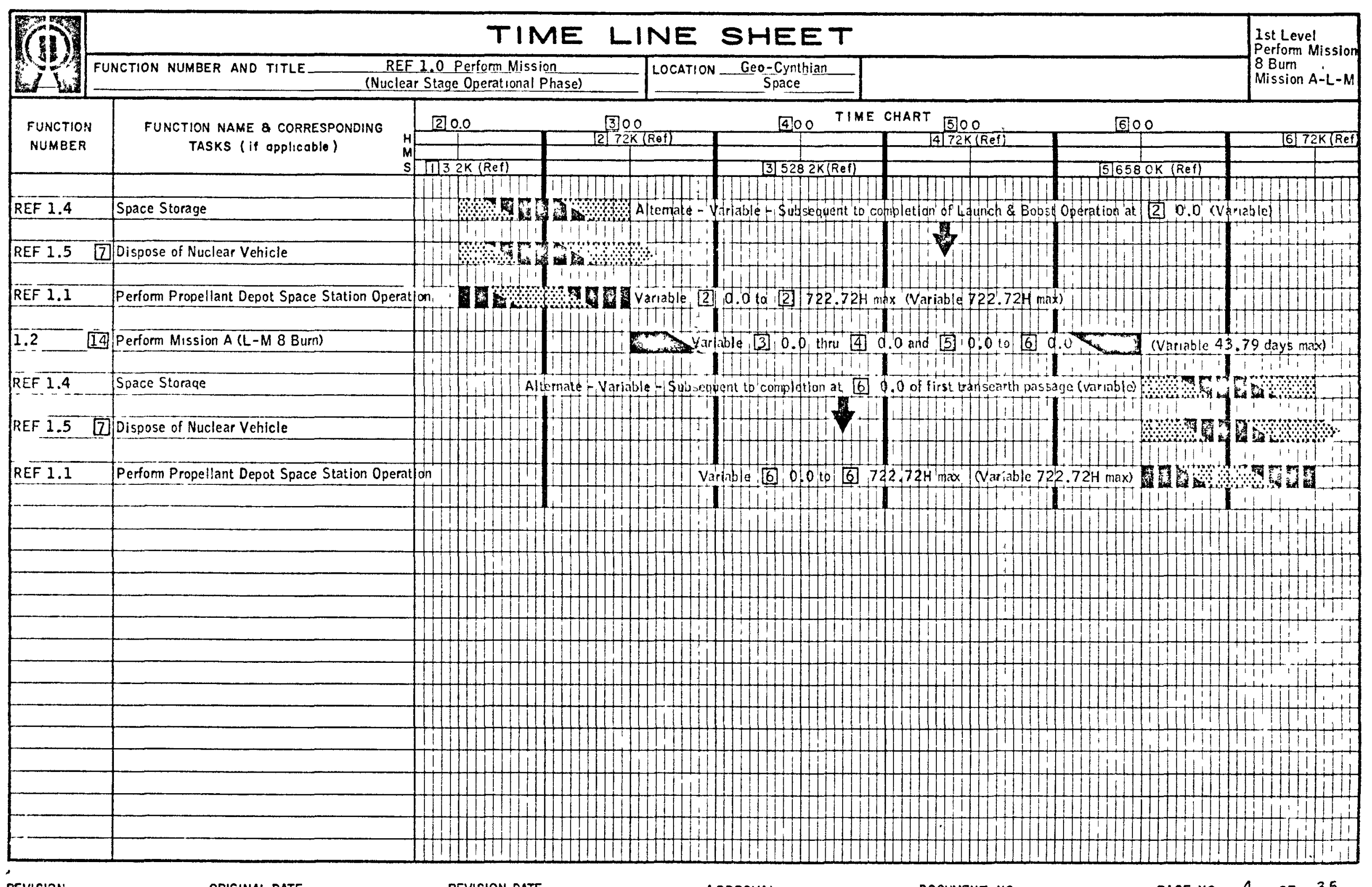




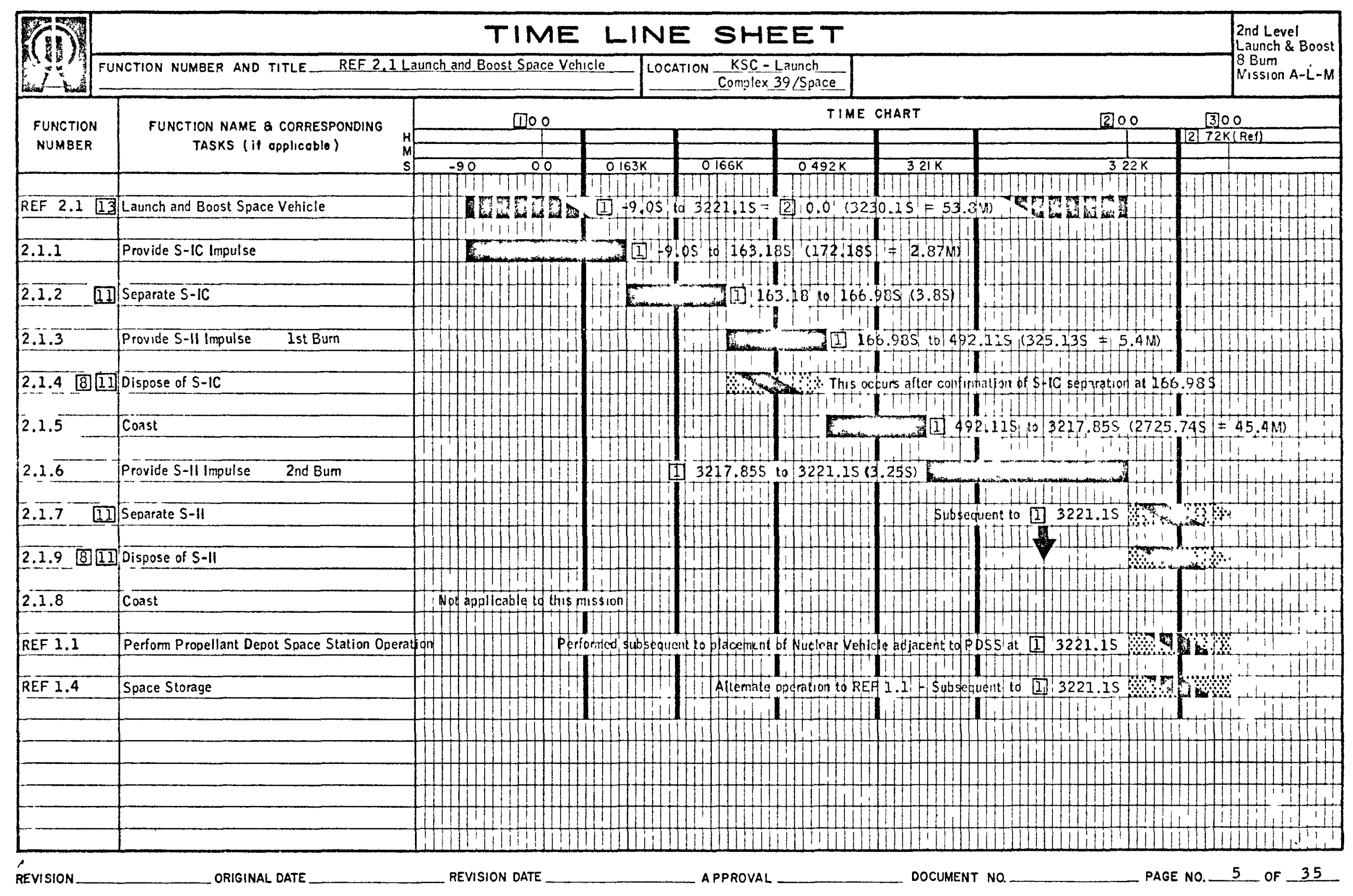




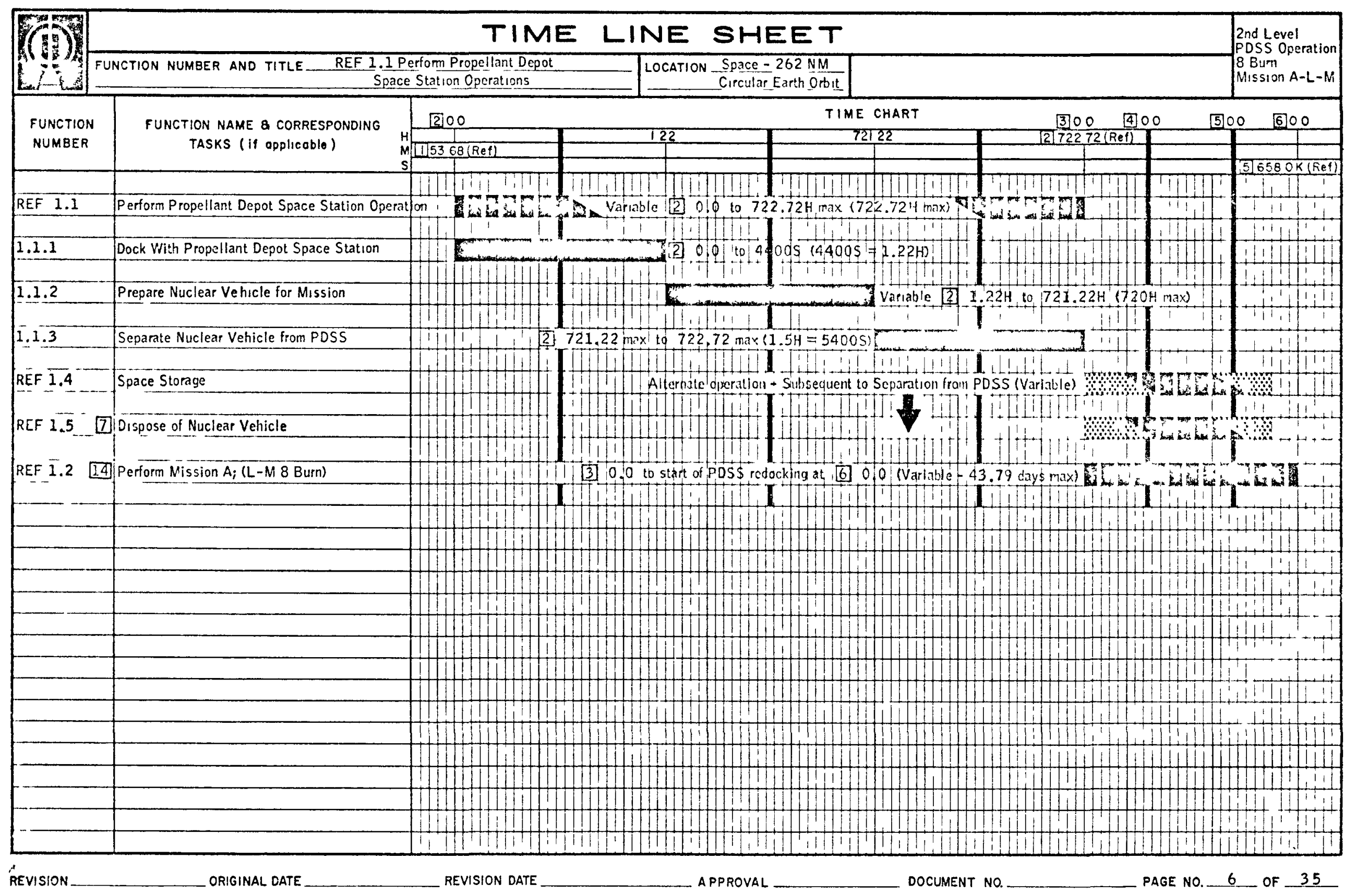




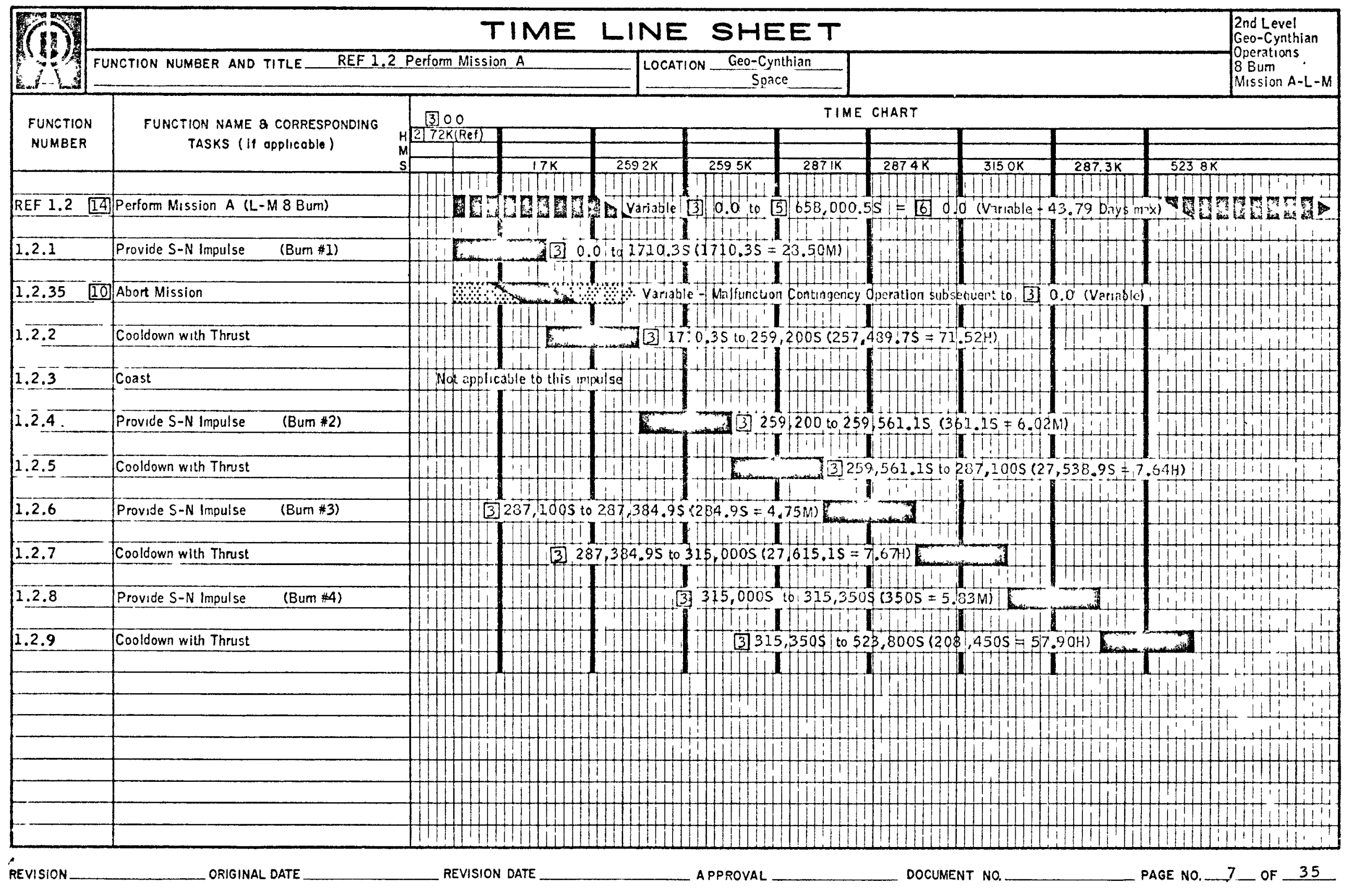




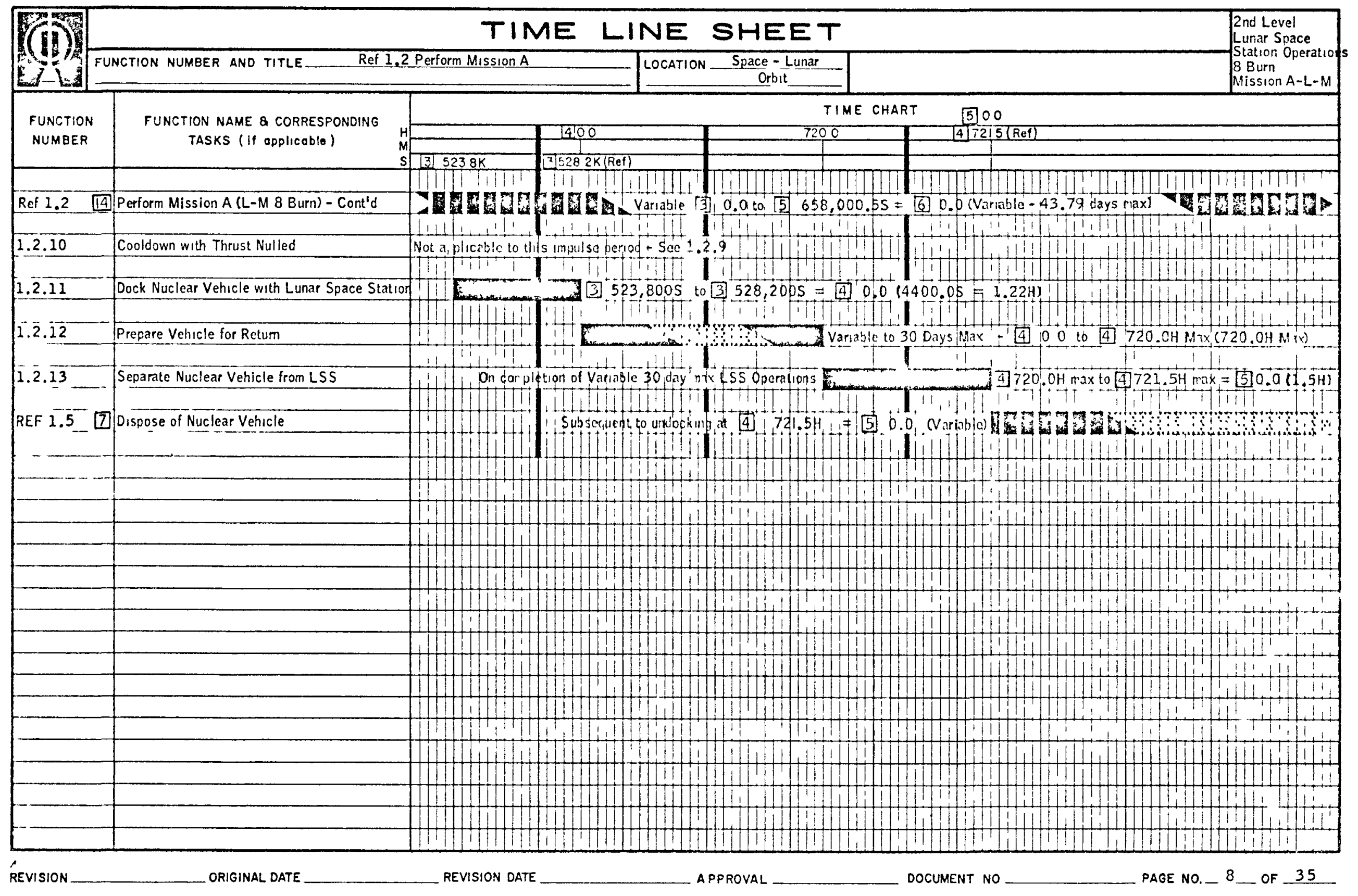




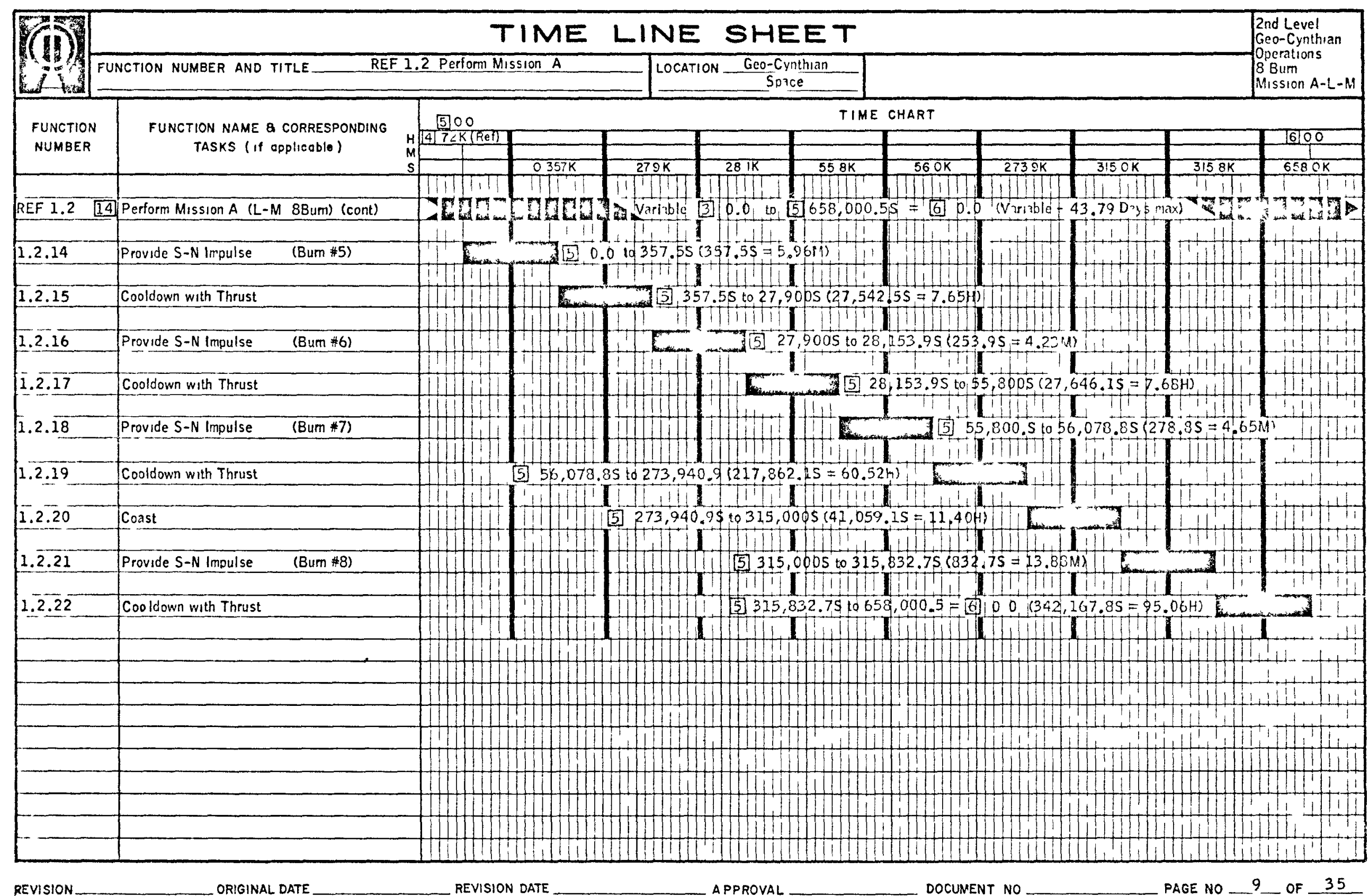




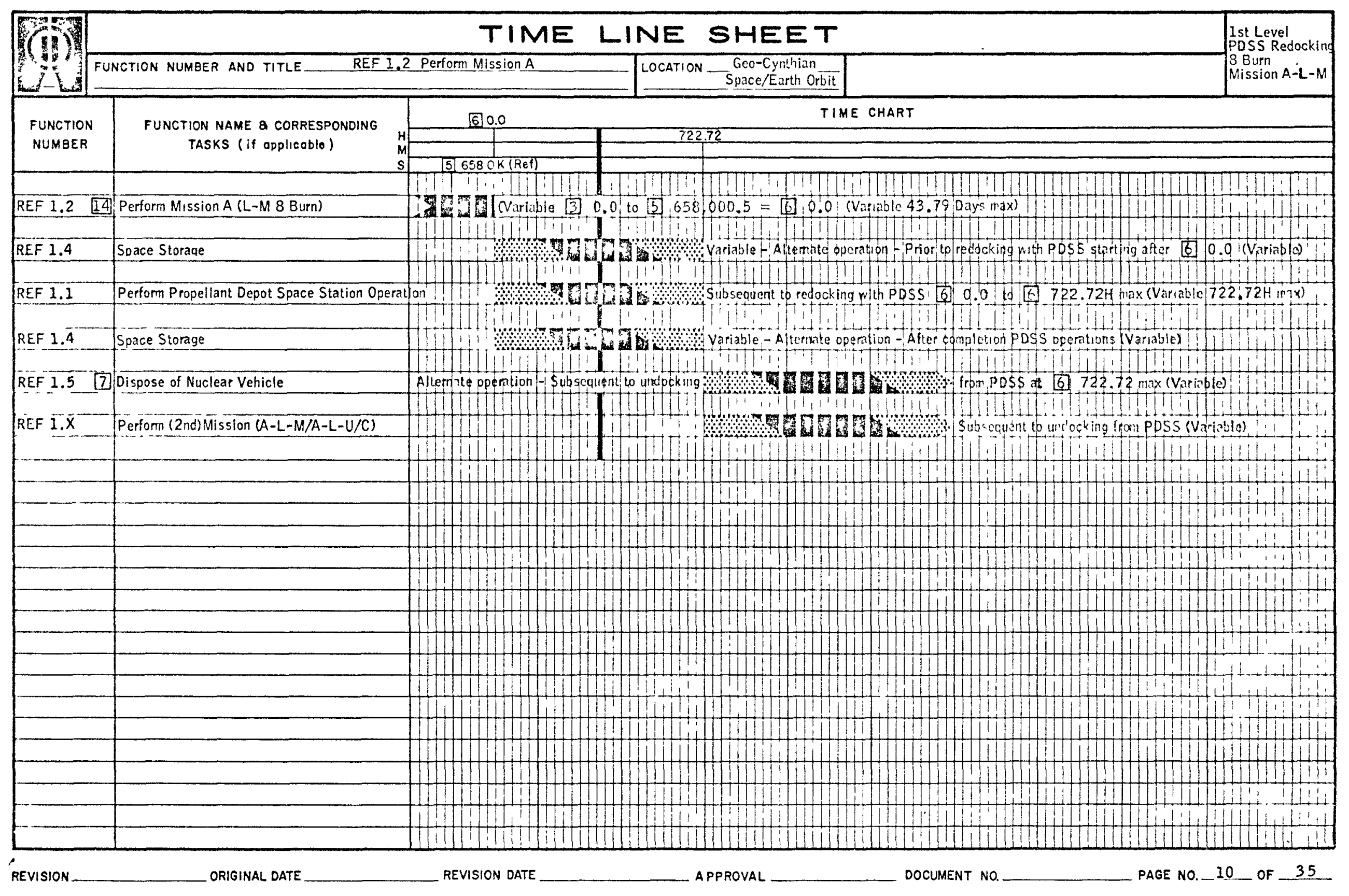




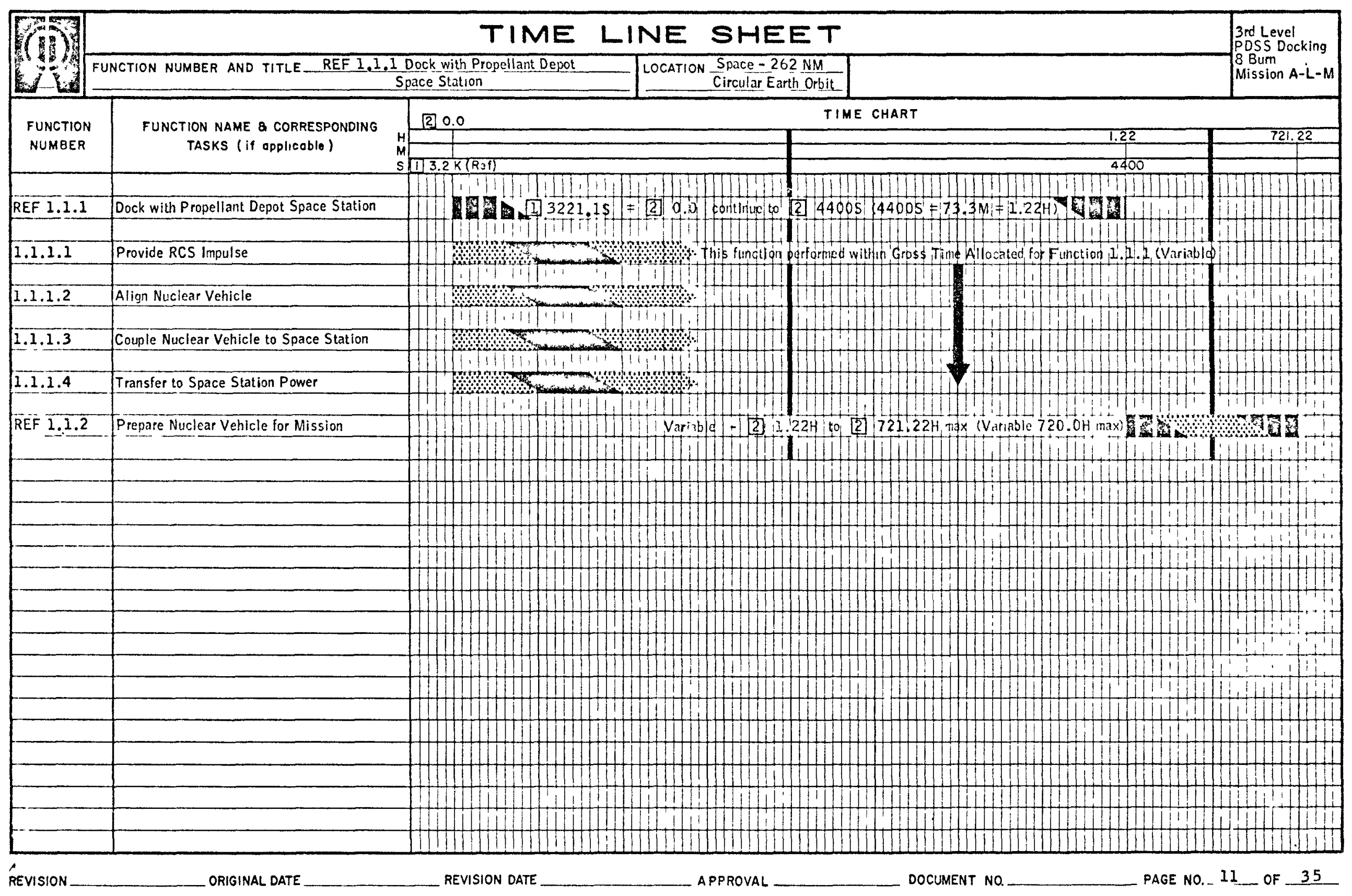




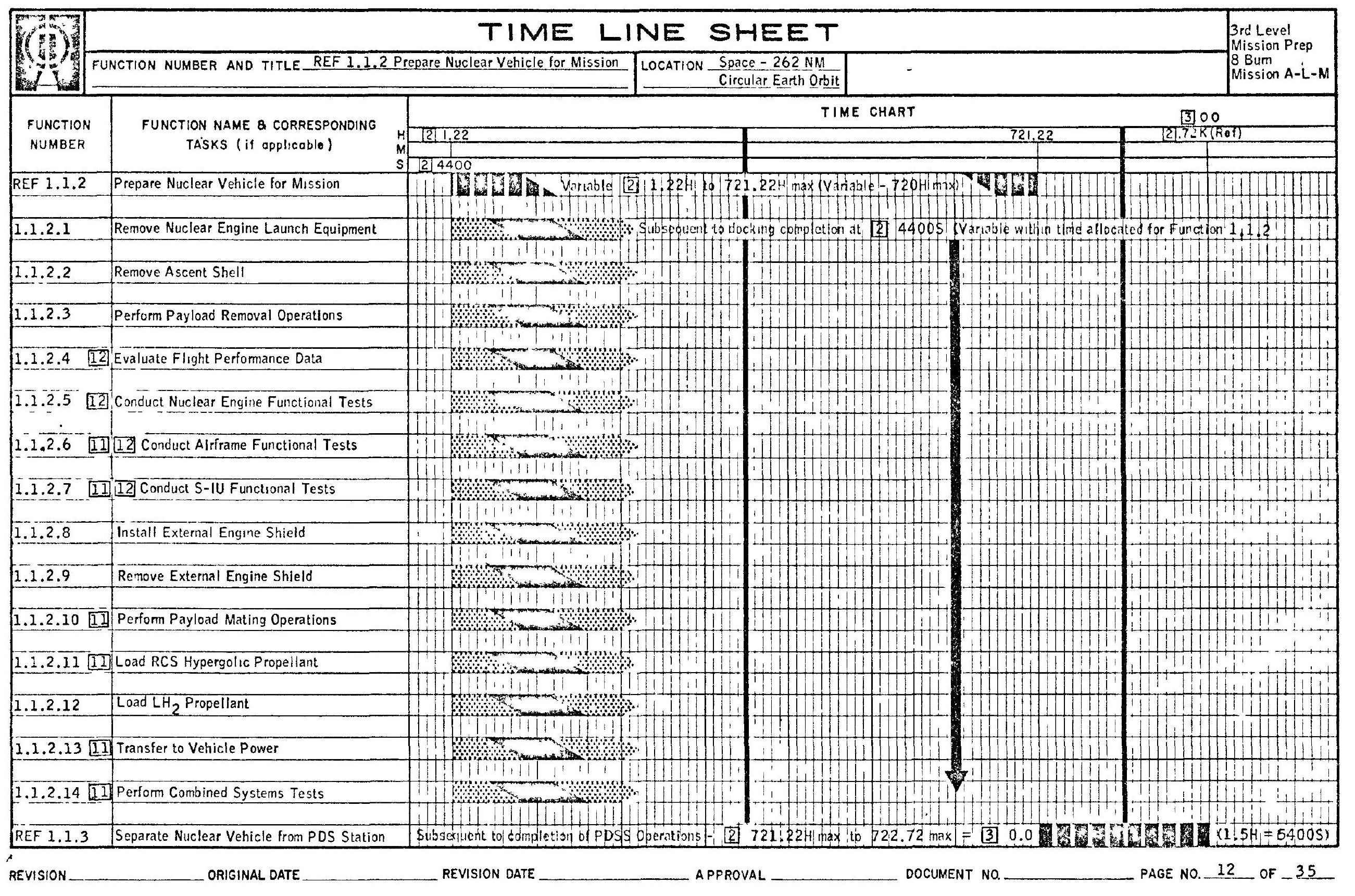




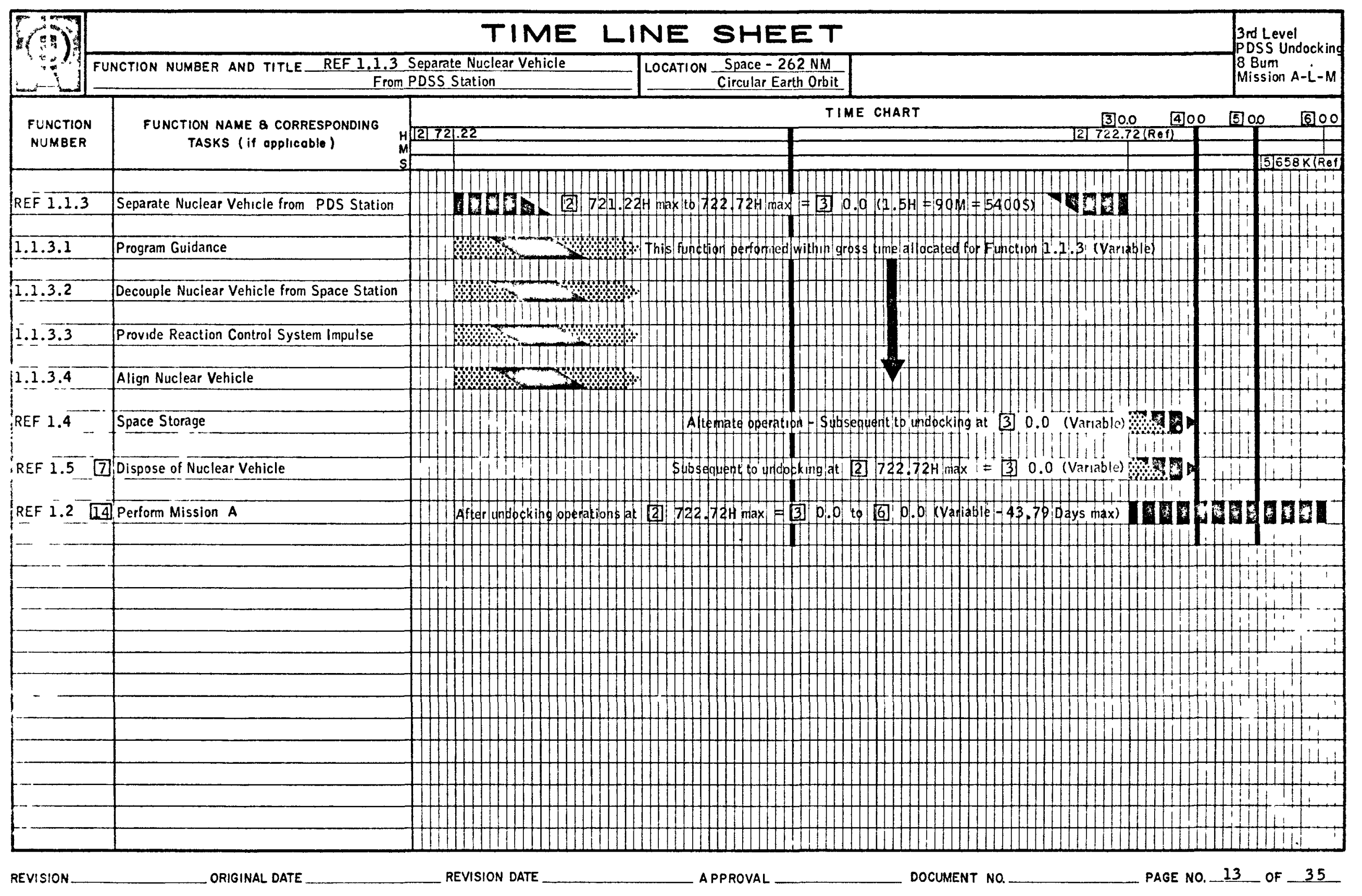




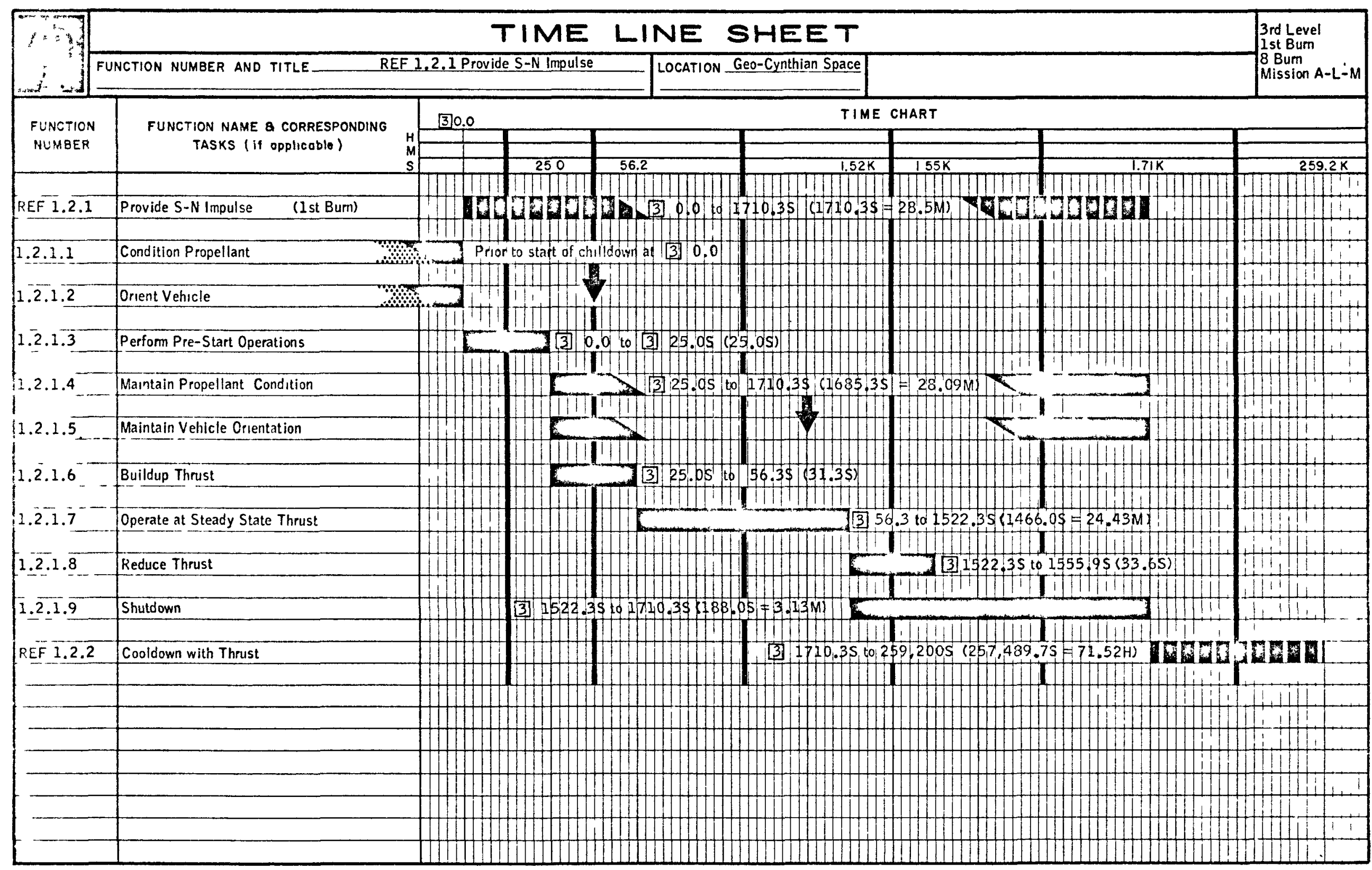




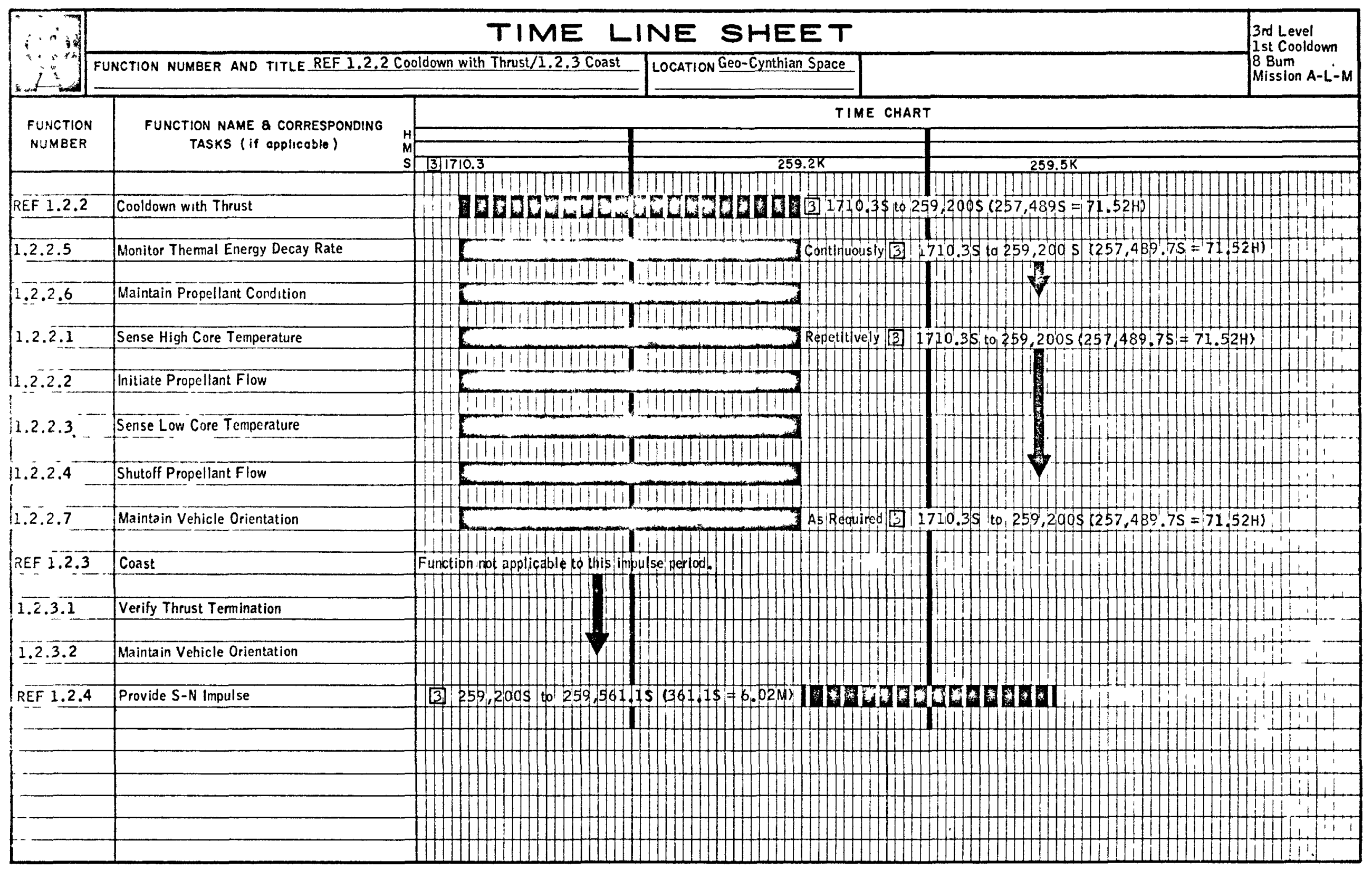




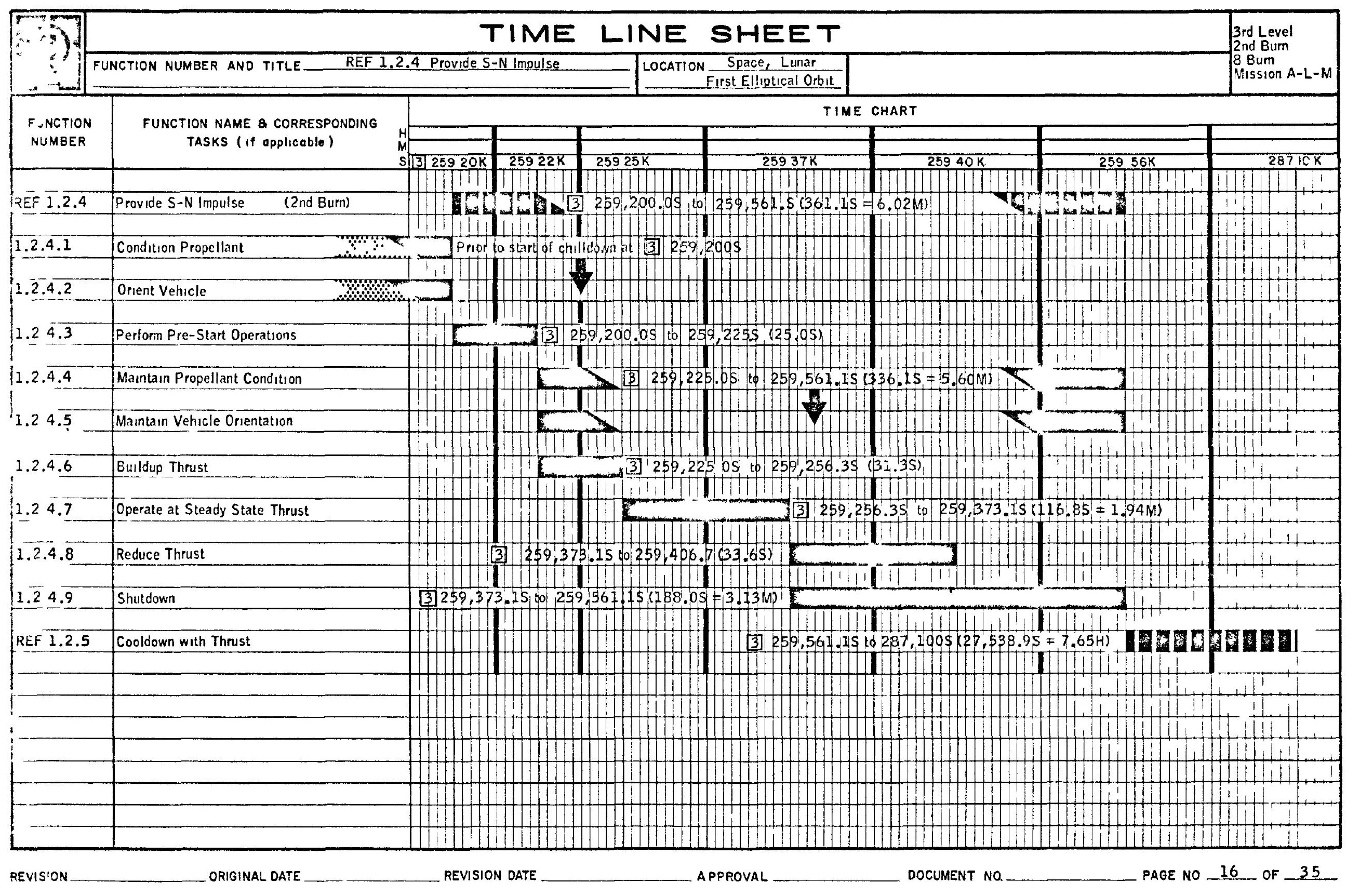




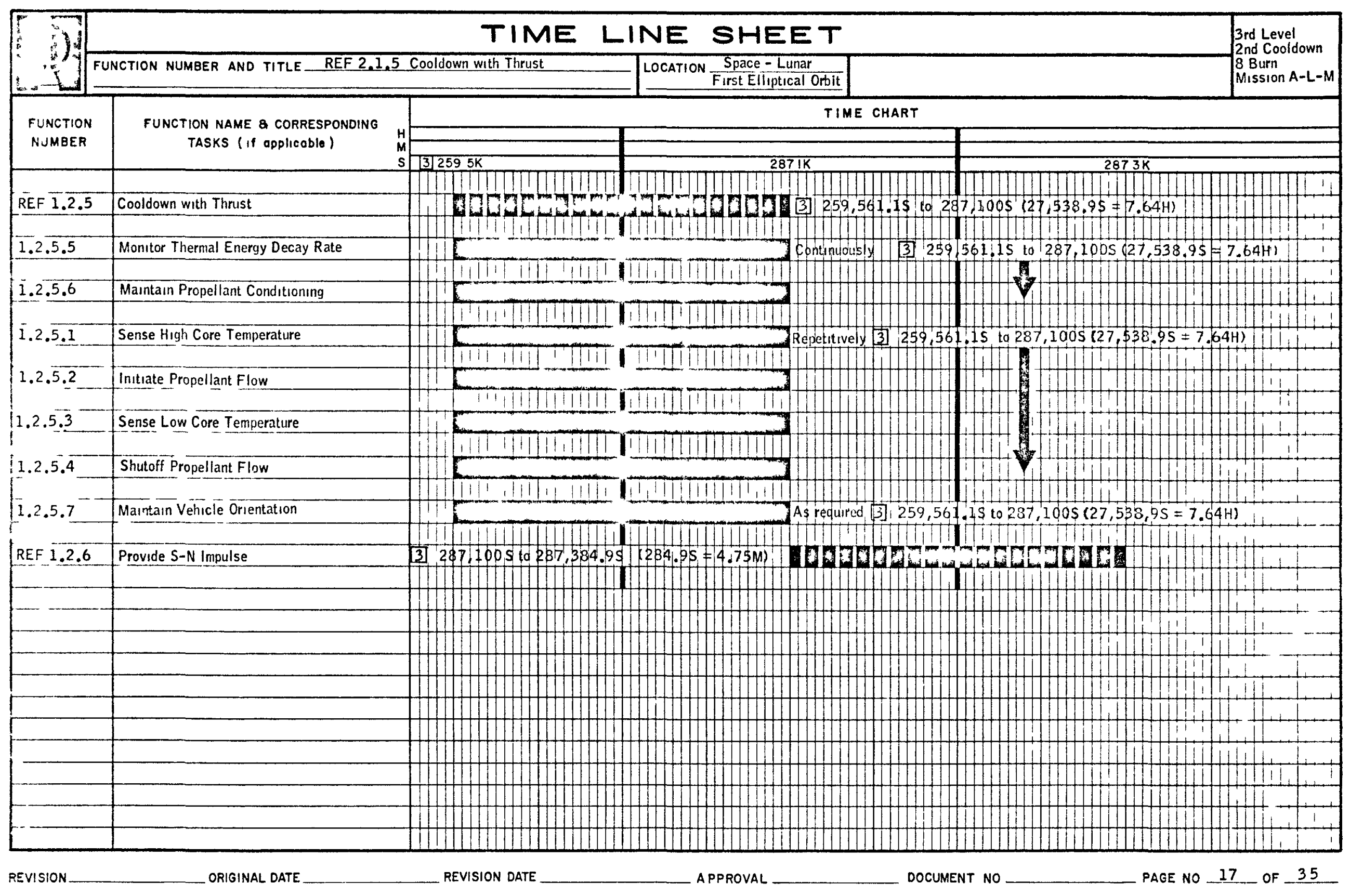




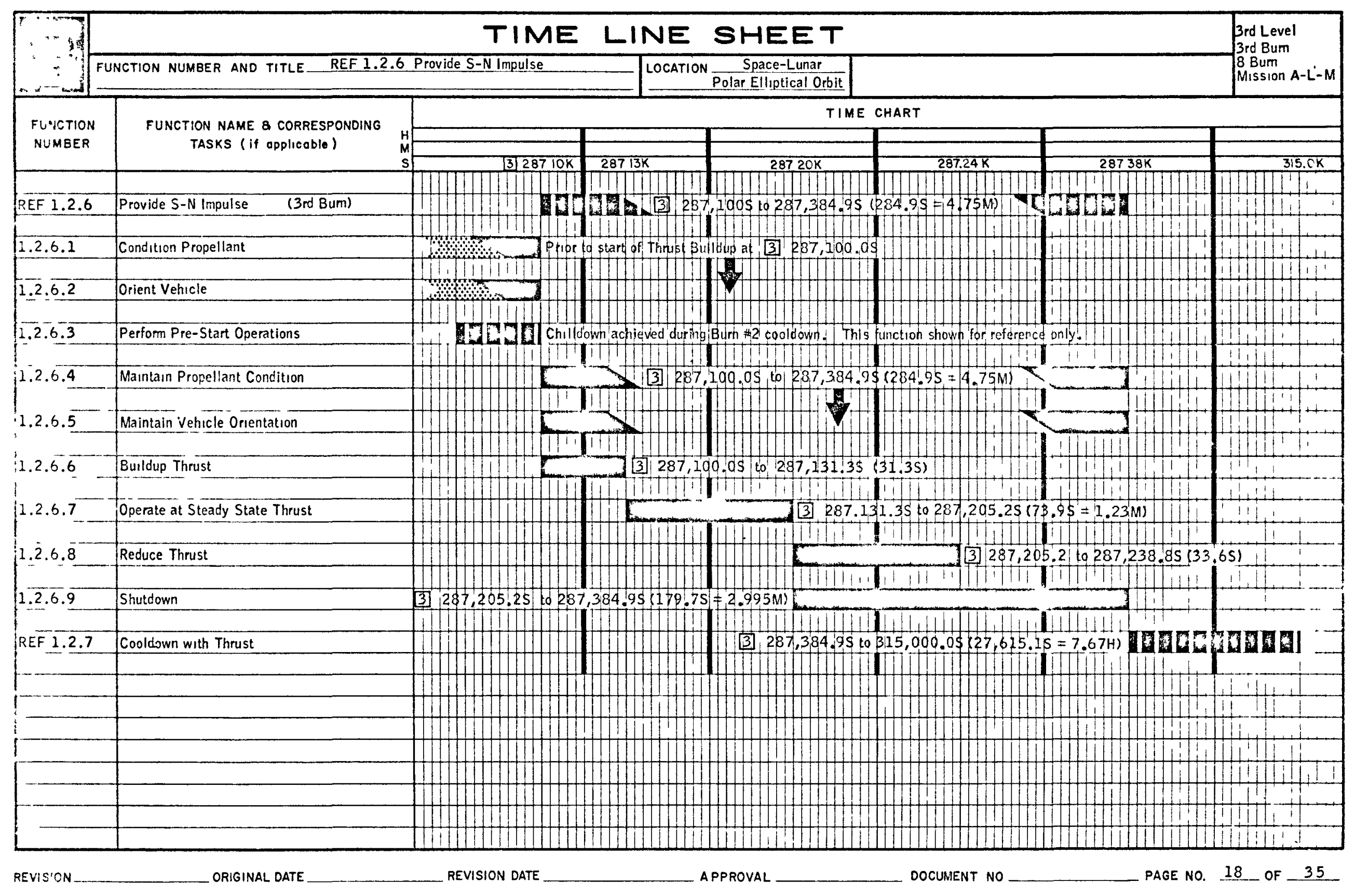




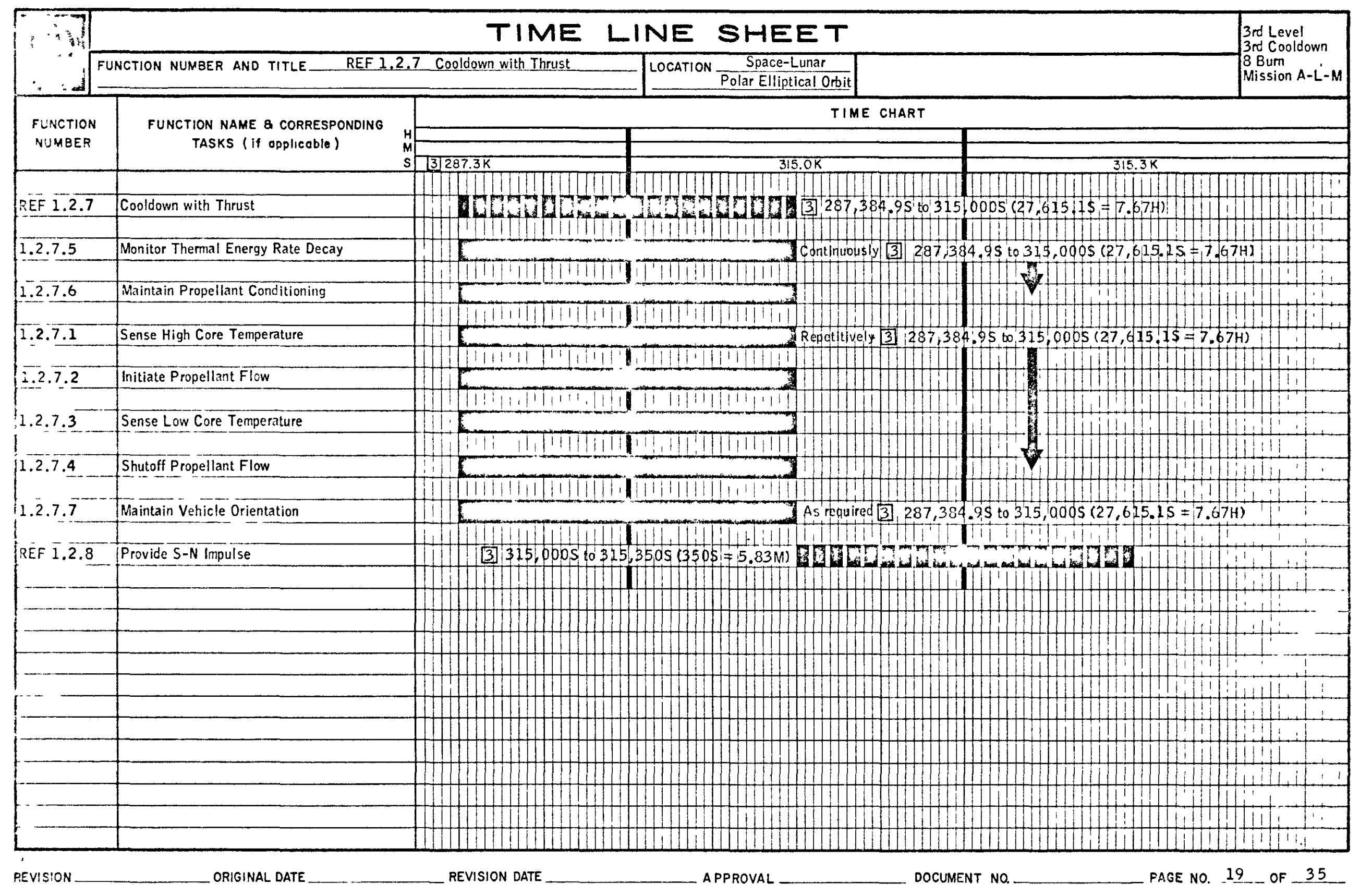




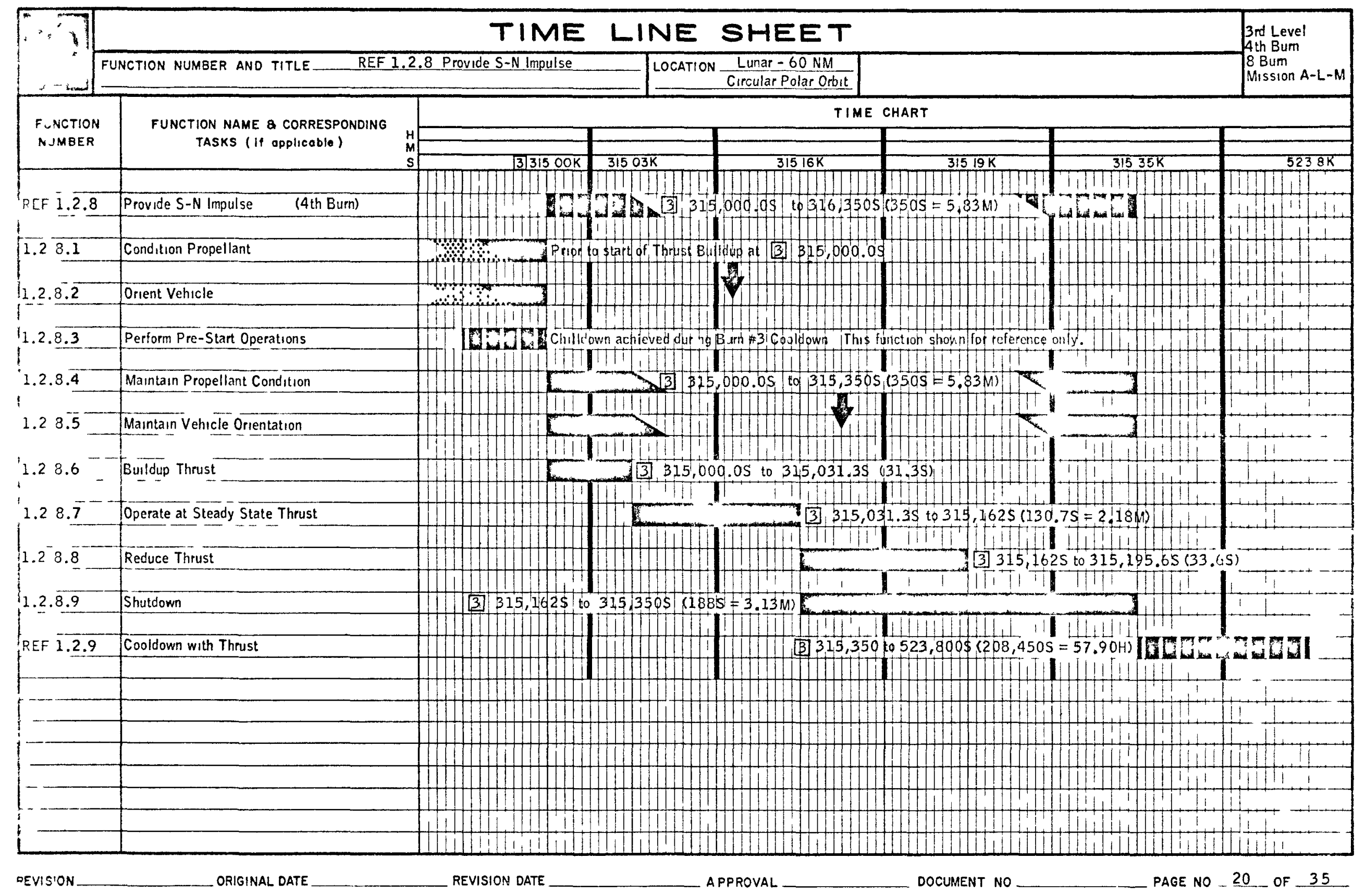




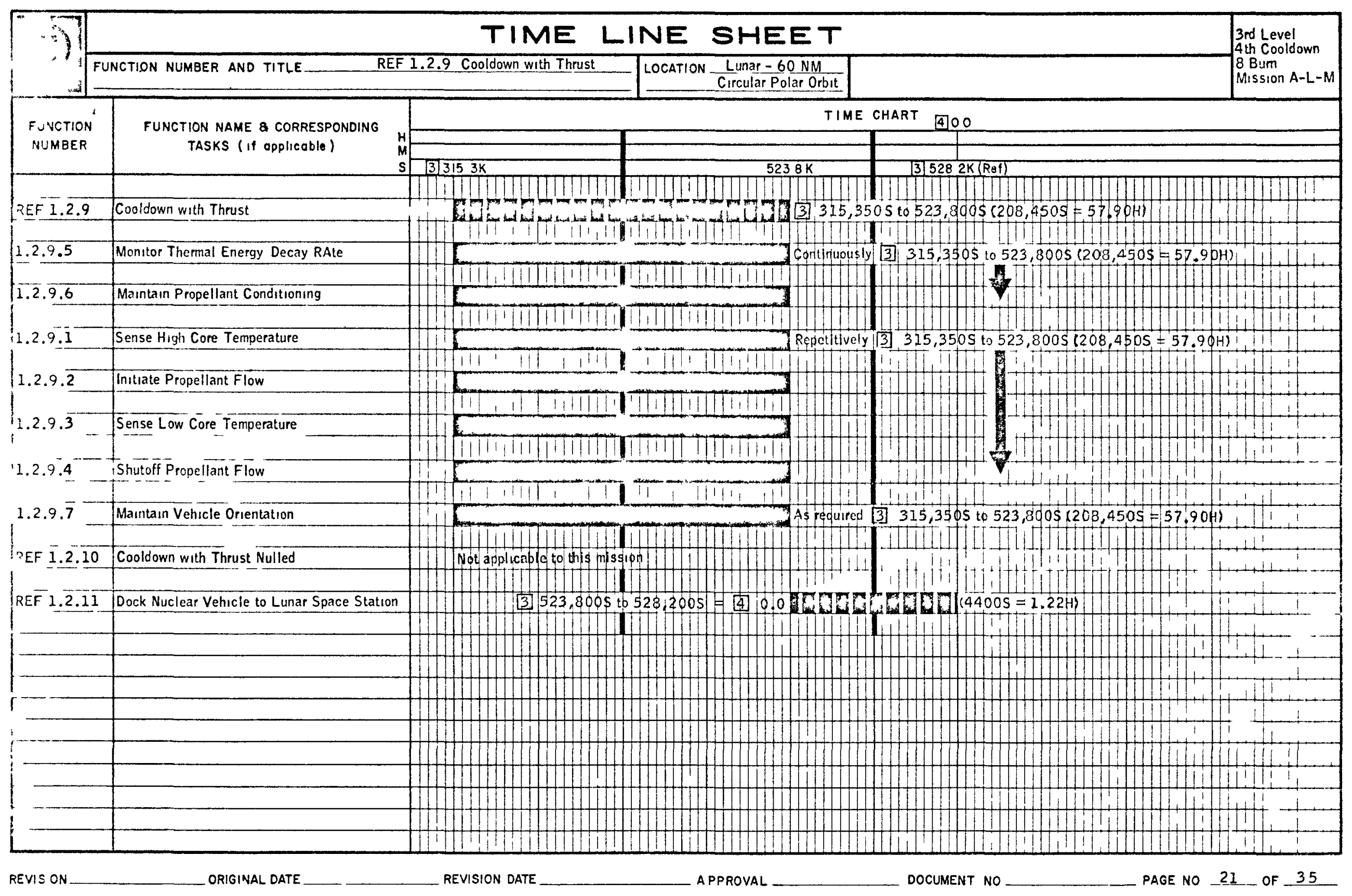




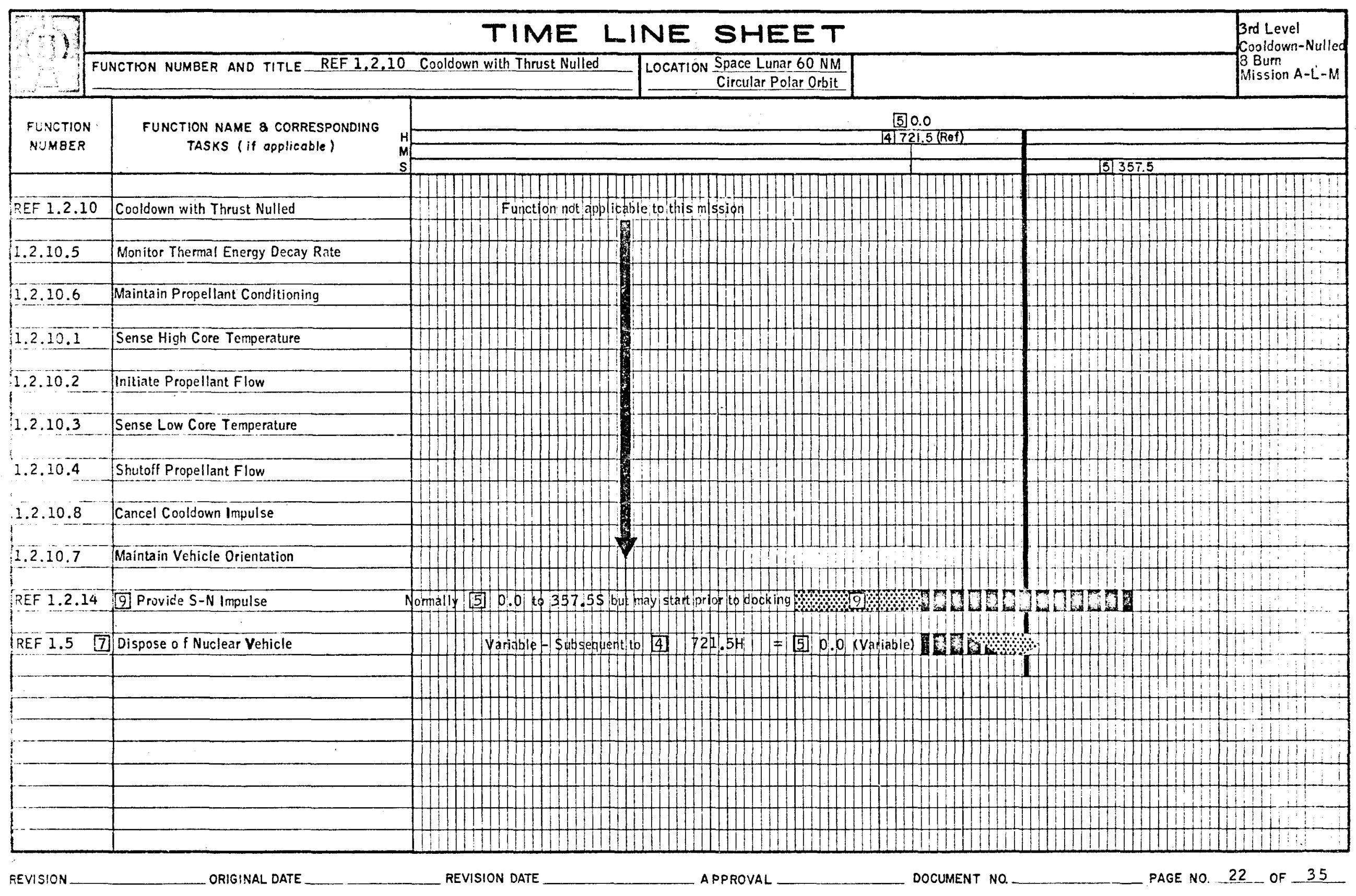




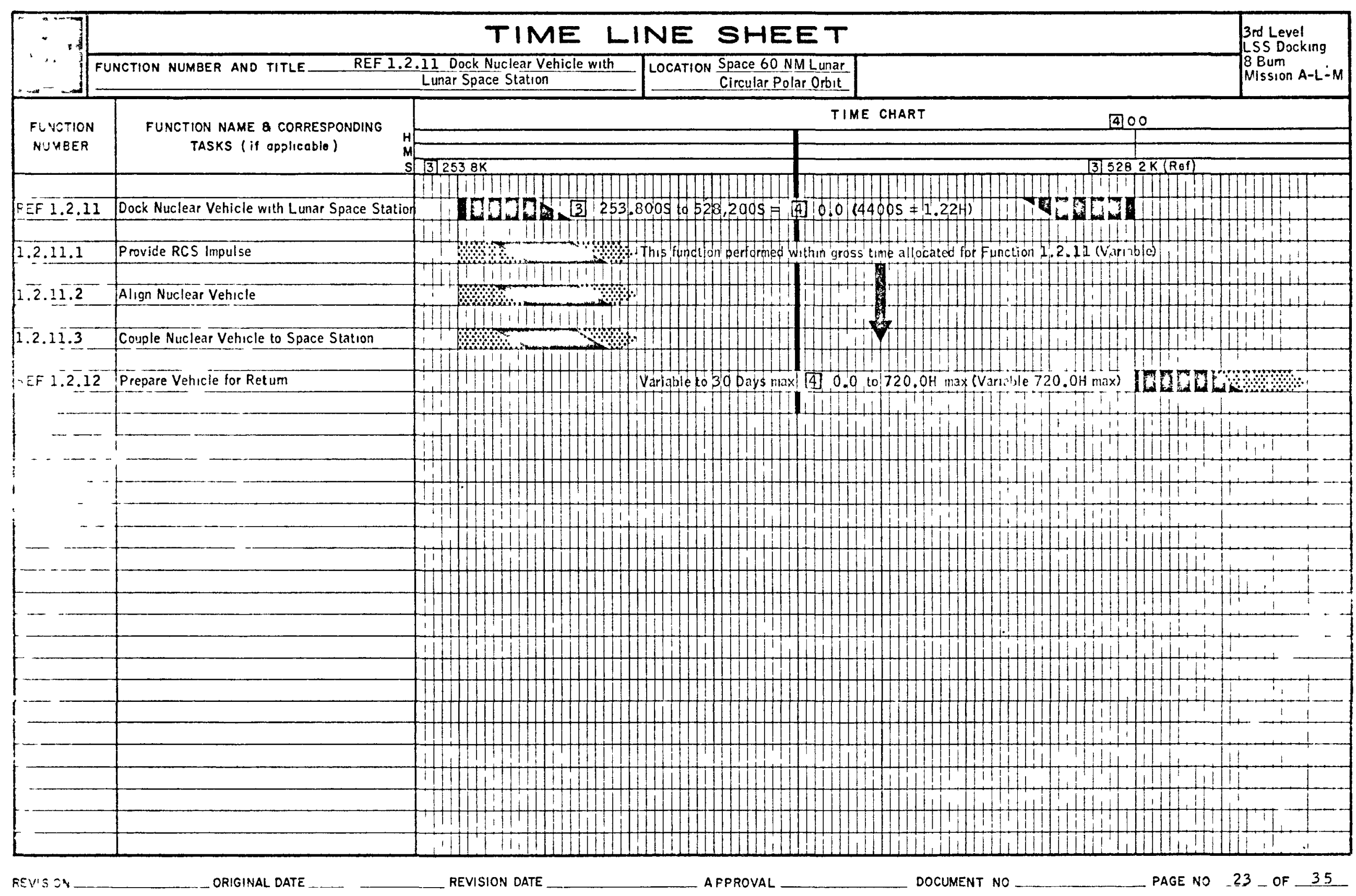




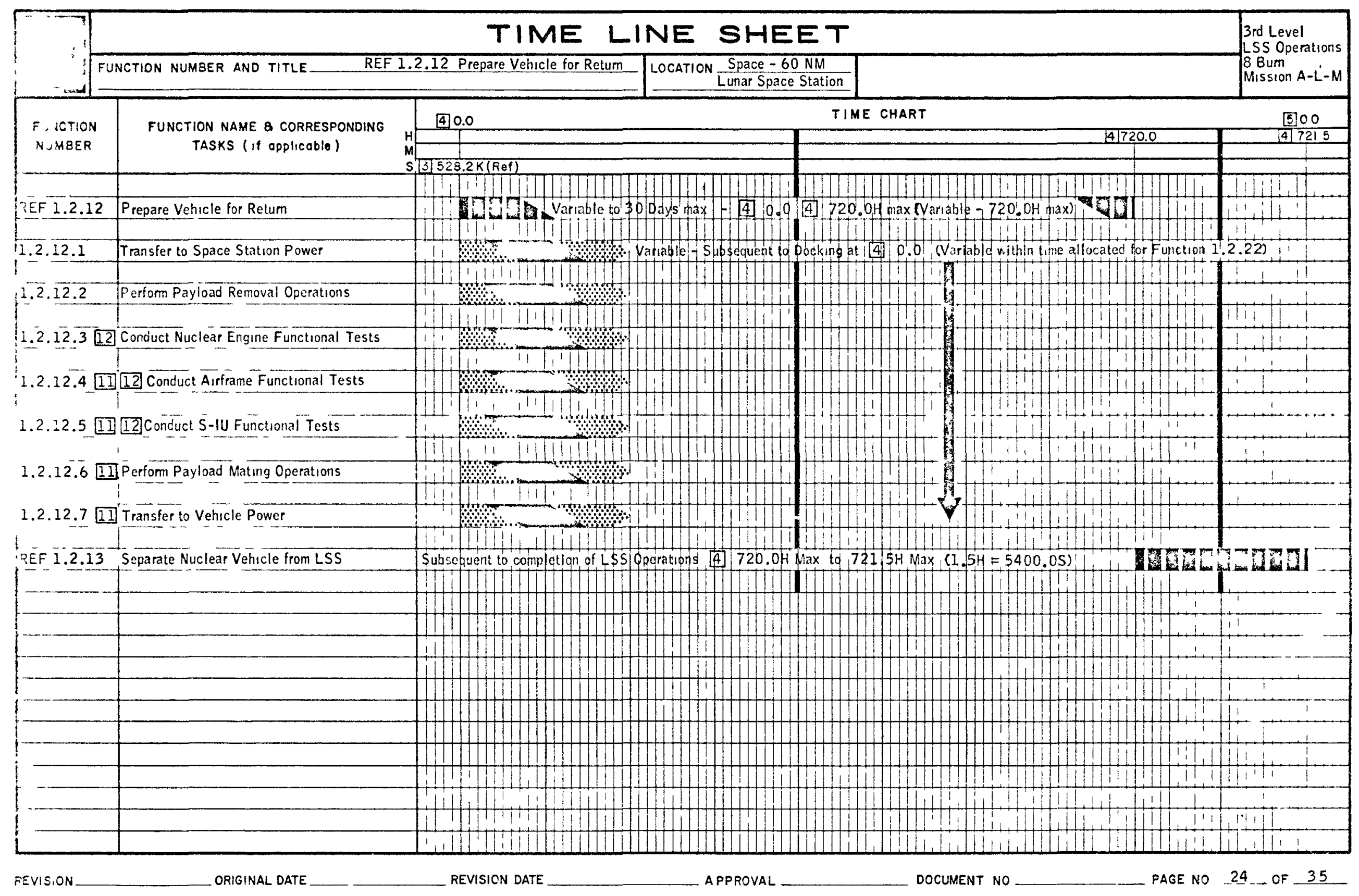




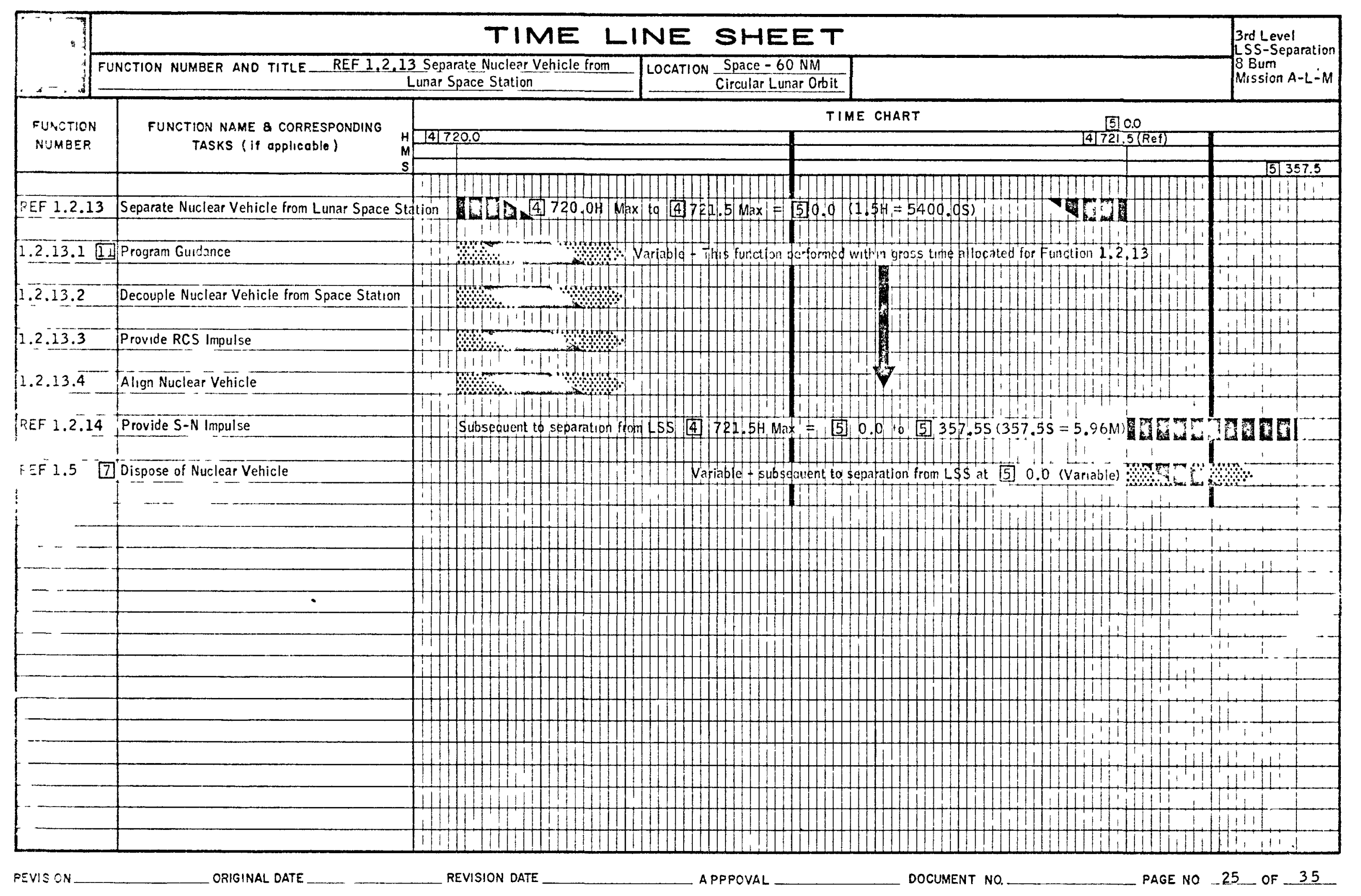




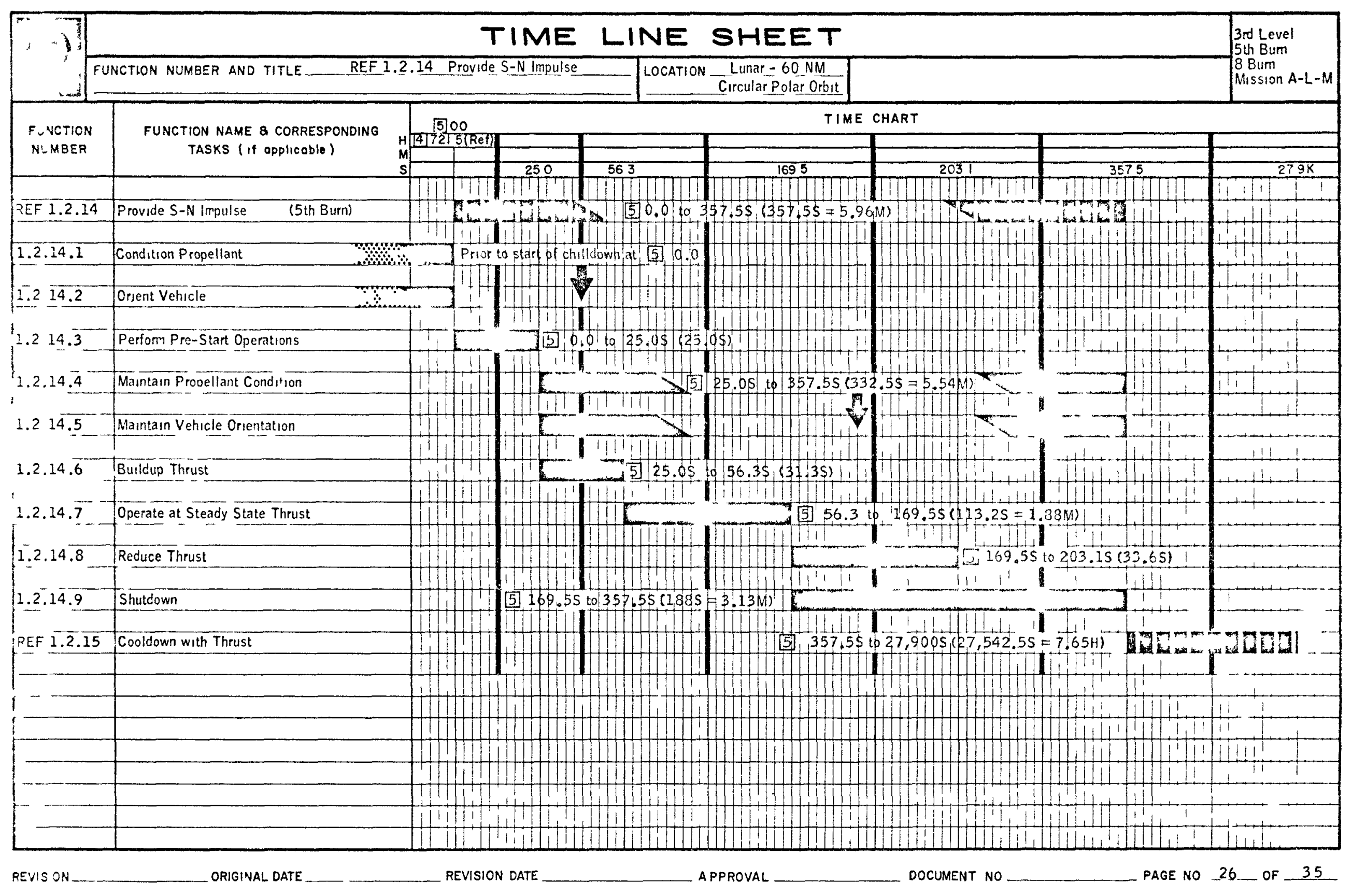




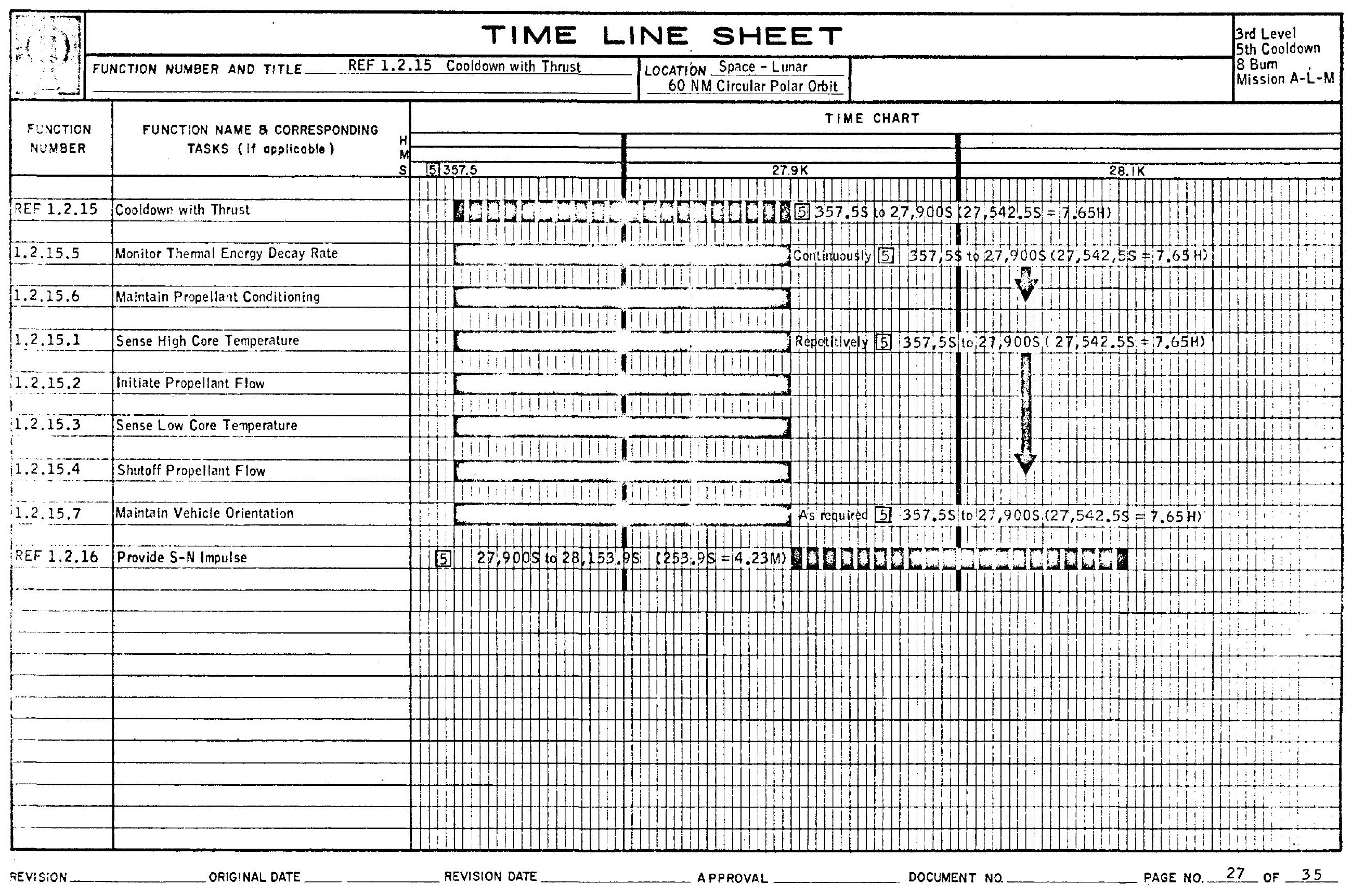




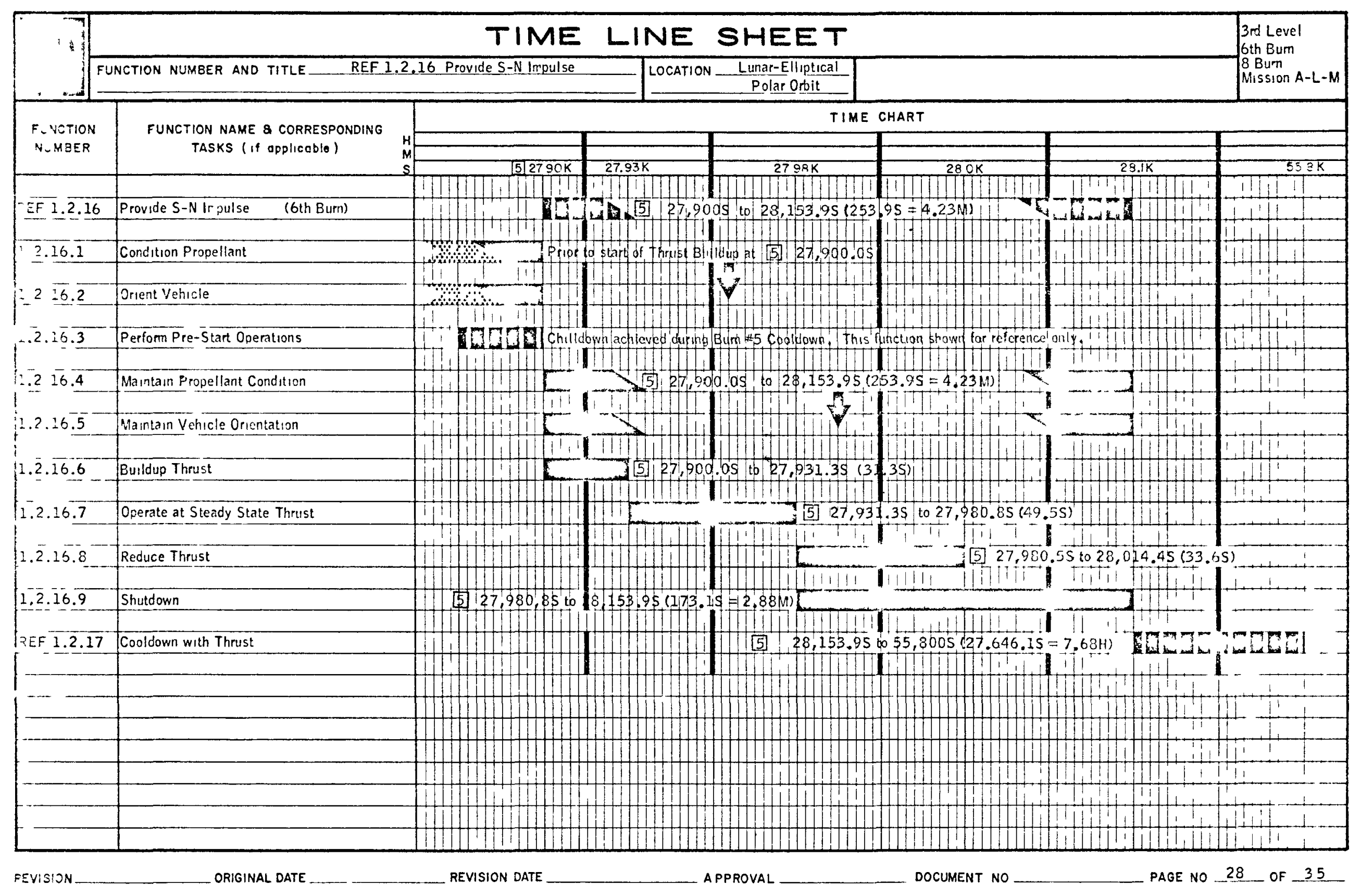




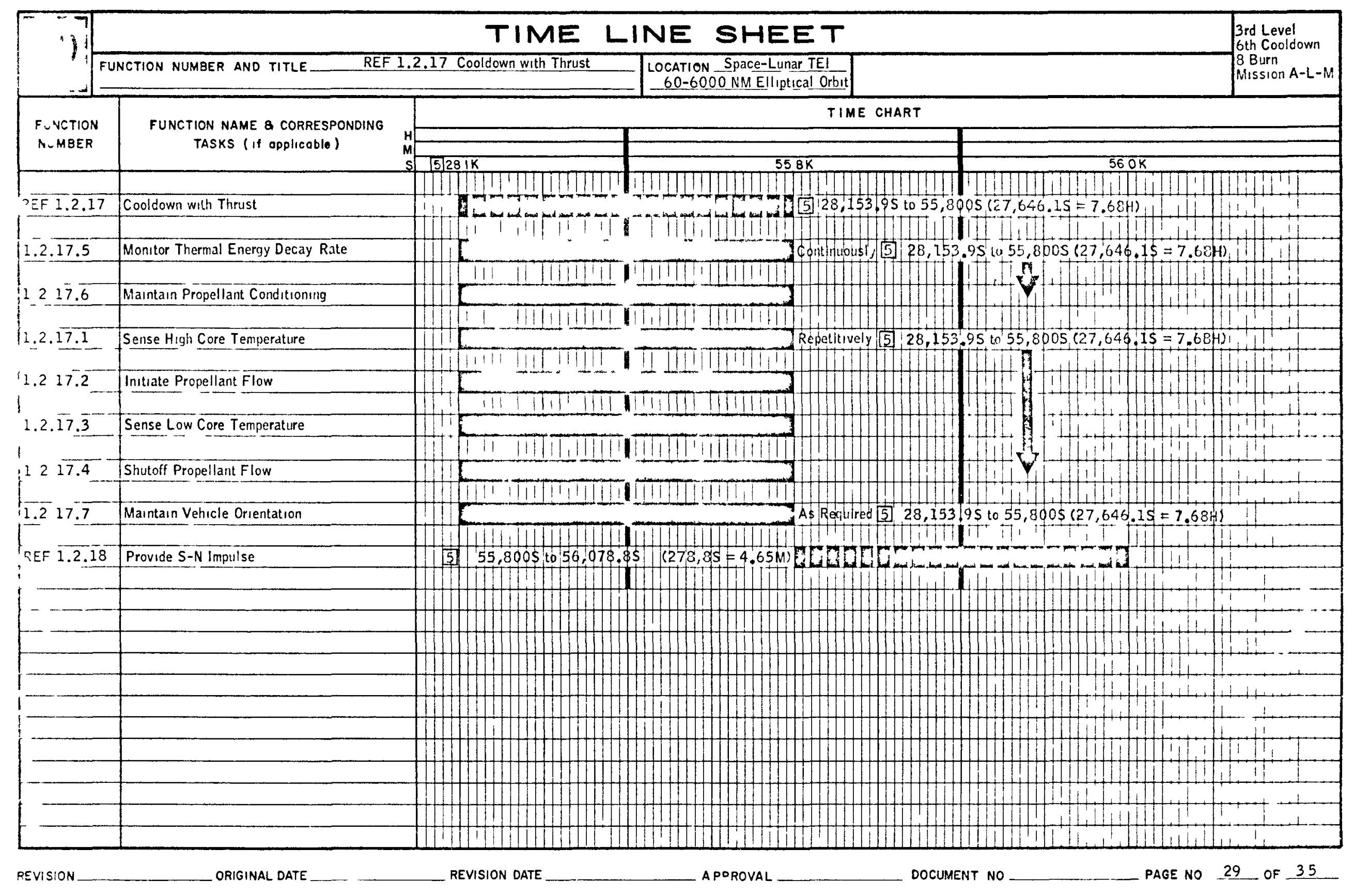




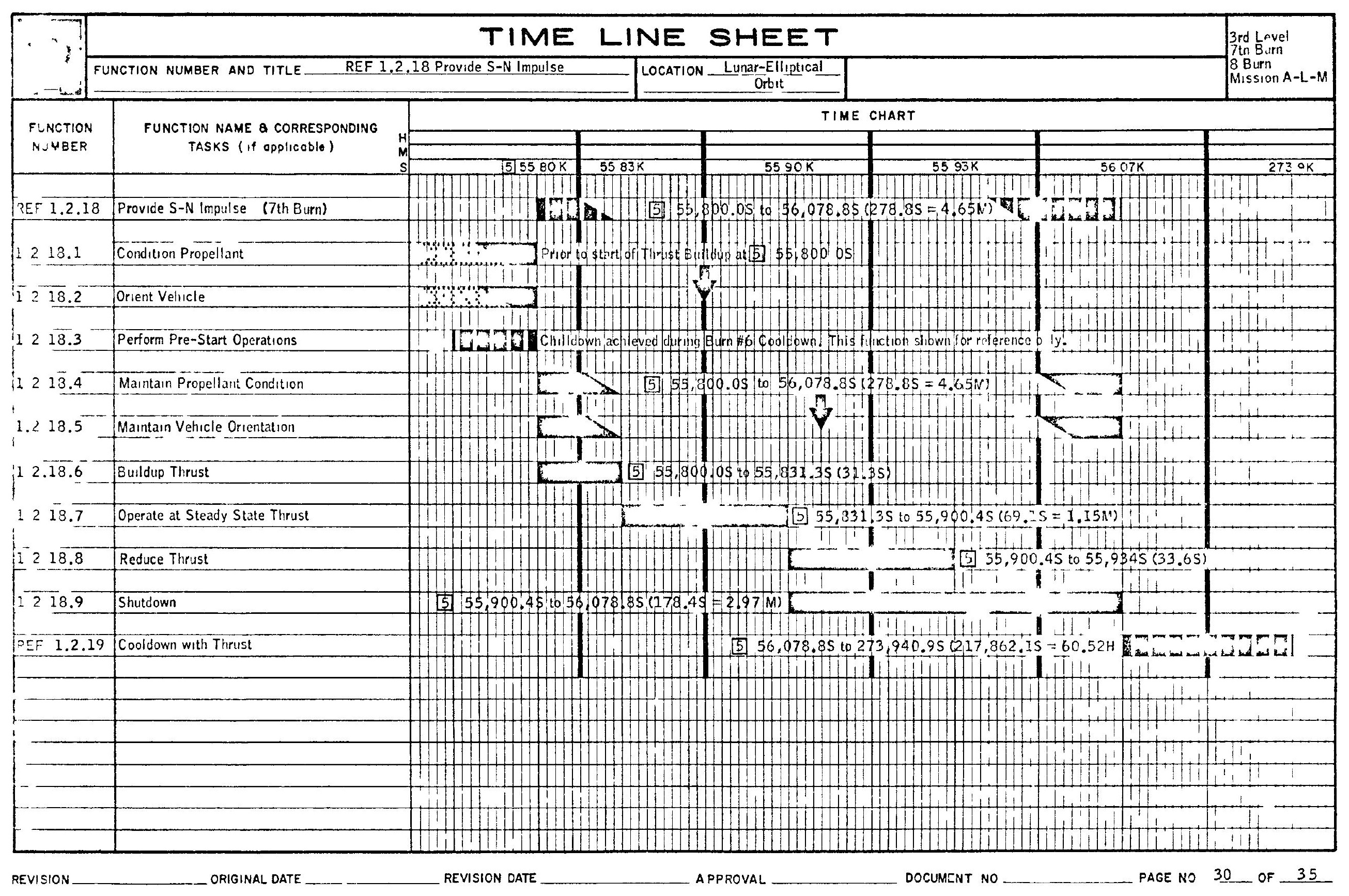




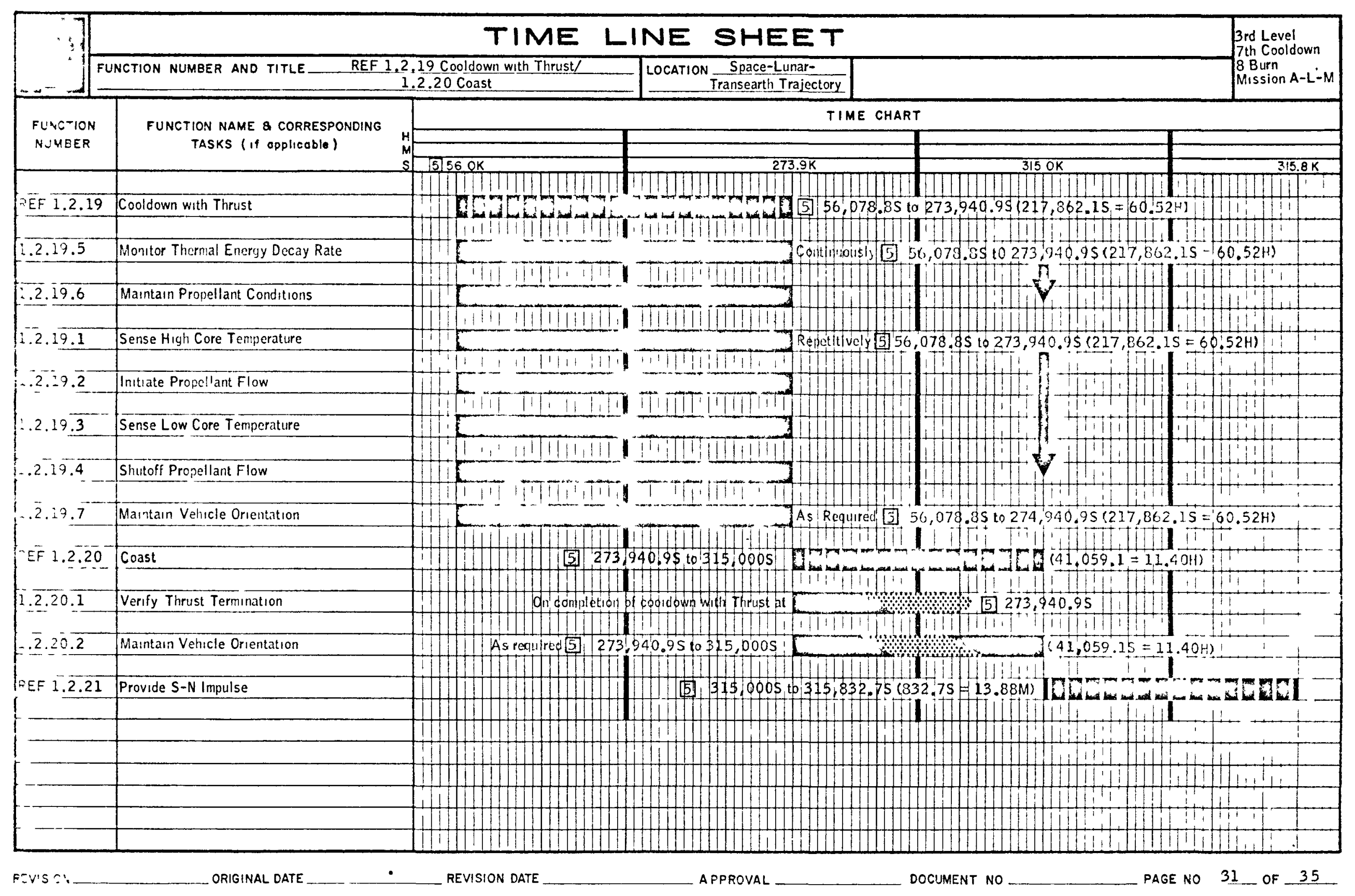




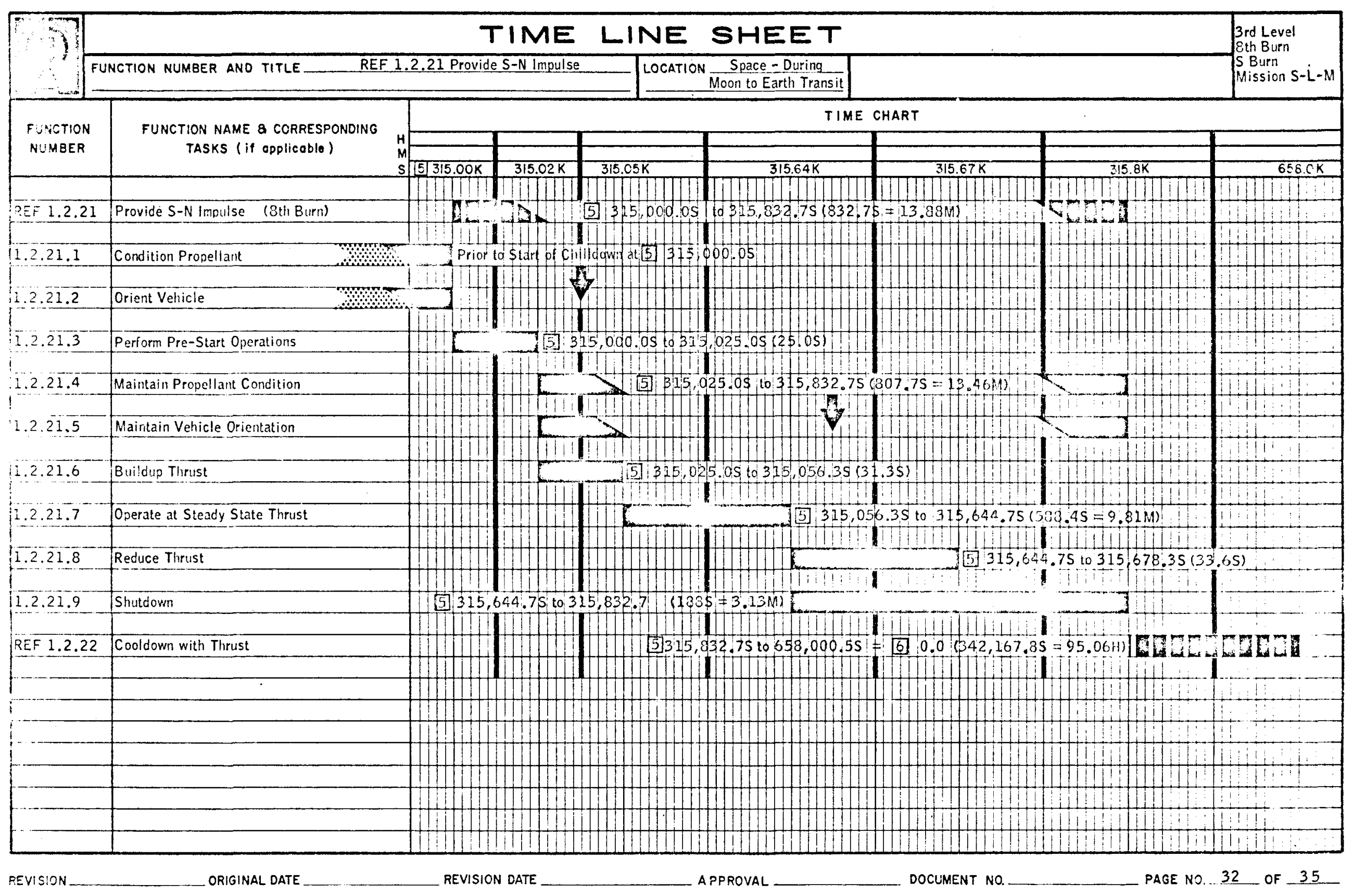




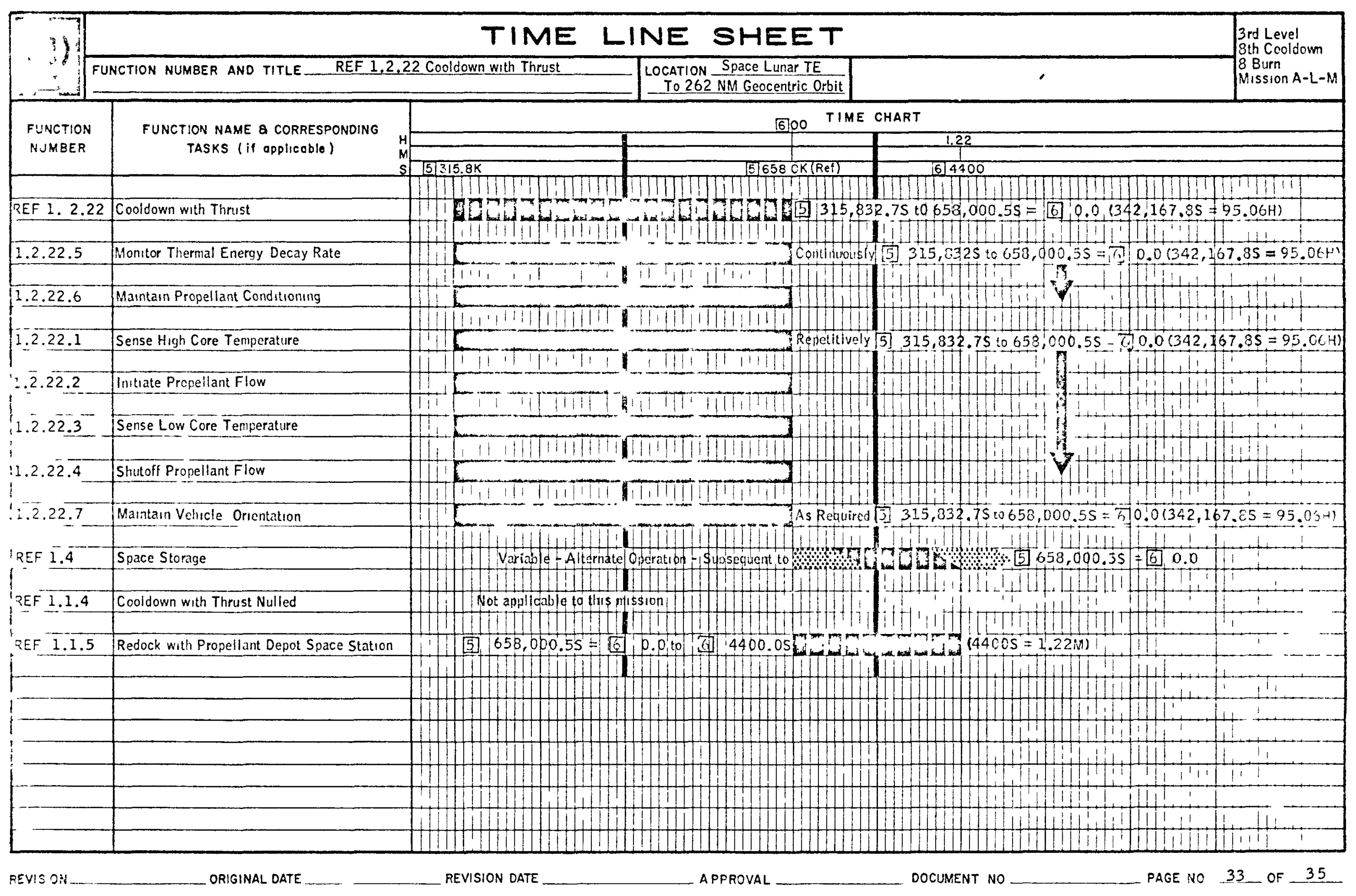




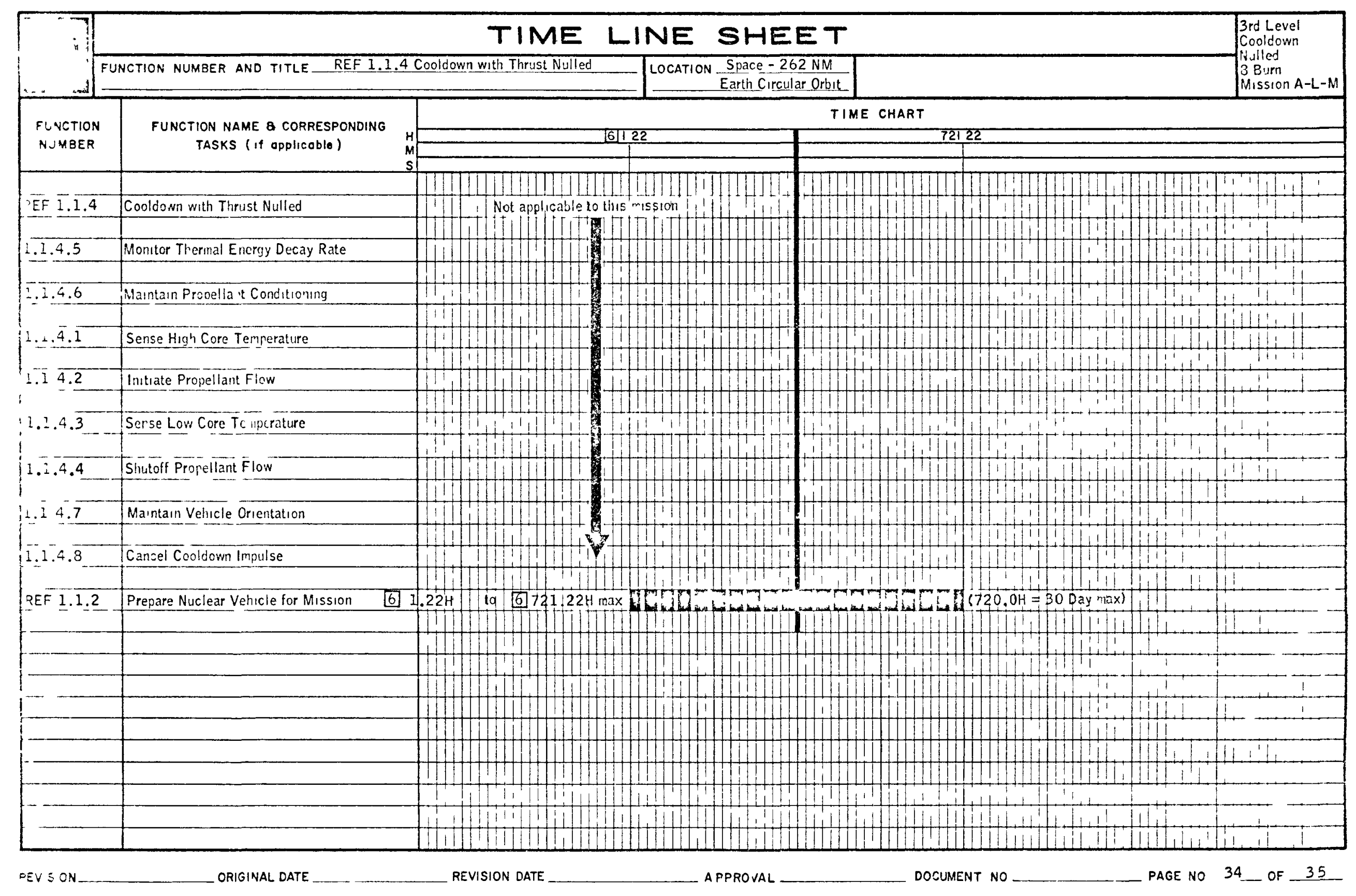




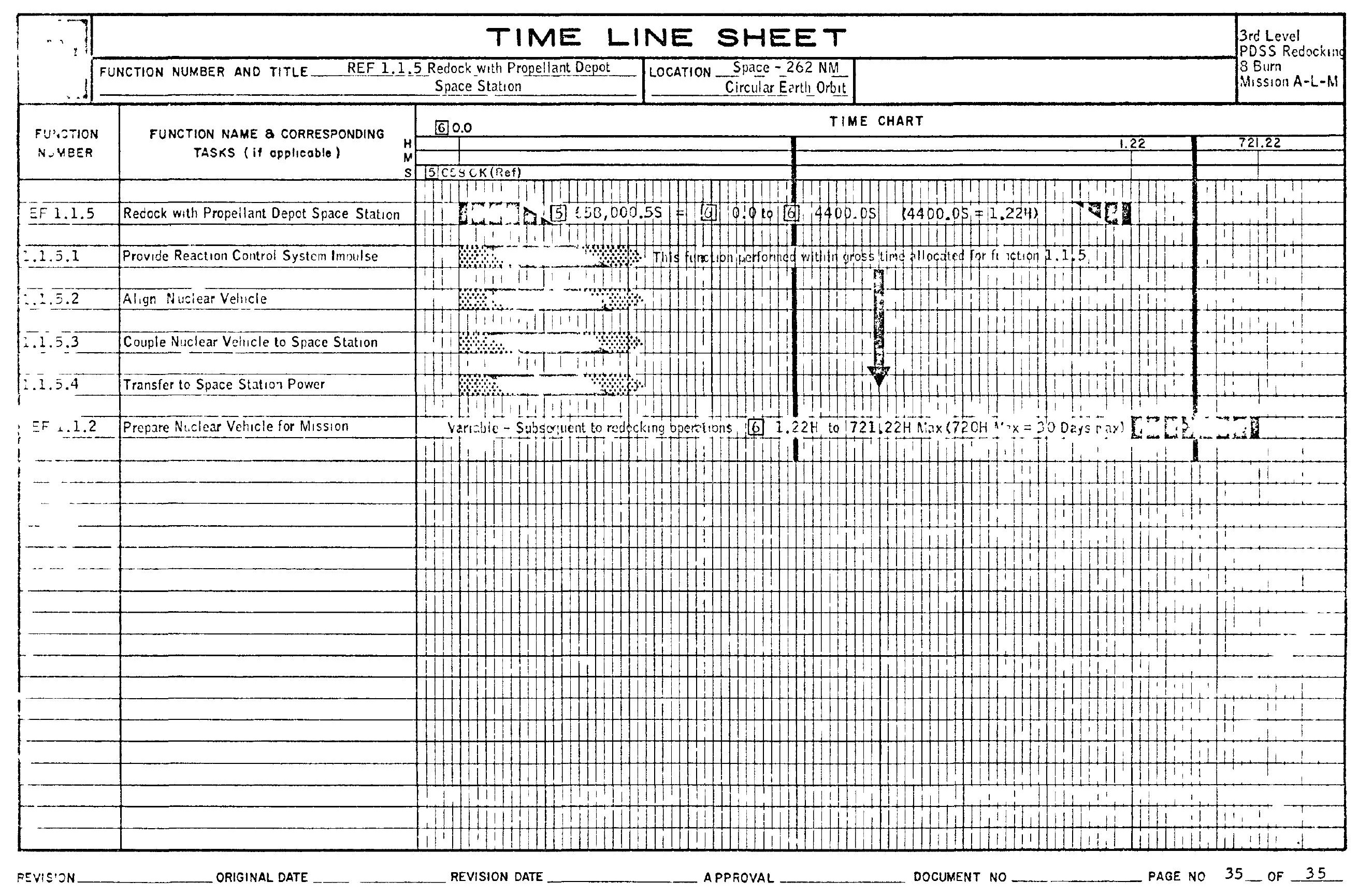

